\title{
13
}

\section{Les poèmes d'éloge du Prophète de Lisān al-Dīn Ibn al-Khāṭīb (713-776/1313-1374 ou 75)}

\author{
Brigitte Foulon
}

Dès le début de la prédication coranique, le Prophète Muhammad a été loué par les poètes qui avaient pris fait et cause pour la religion naissante. Le plus célèbre de ces laudateurs est sans nul doute Ḥassān b. Thābit ${ }^{1}$, qui avait déjà acquis une grande renommée de panégyriste avant l'islam, notamment auprès des rois lakhmides et ghassānides. Ka'b b. Zuhayr², descendant d'une famille sétant illustrée par la poésie durant la Jāhiliyya, se distingua aussi dans ce domaine. Sa célèbre qașida, Bānat Su'ād, première d'une série de Mantle odes, pour reprendre l'expression de Susanne Pinckney Stetkevych, fut composée alors qu'il était menacé de mort après avoir satirisé le Prophète. Cette première Burda, qui relève du sous-genre «poème d'excuses » (itidhāriyya) et s'inspire de la célèbre qaṣīda d'al-Nābigha al-Dhubyānī $\overline{\mathbf{}}^{3}$ adressée au roi lakhmide al-Nu'mān ${ }^{4}$, met l'accent sur les qualités guerrières du Prophète en l'assimilant à un lion féroce. Elle respecte totalement la structure tripartite des poèmes antéislamiques en faisant précéder l'éloge (le gharad du poème) par un nasīb et un rahìl.

Après la mort du Prophète, le panégyrique du Prophète (madīh nabawī) entamaunelongue évolution et ne futguère fixéavant la période post-classique ${ }^{5}$. Les madāih composés durant la période classique virent essentiellement le jour dans le cadre de la poésie d'éloge shīite, centrée autour des figures de 'Alī et des ahl al-bayt. Certaines caractéristiques de ces compositions shīites annoncent déjà les textes de la période ultérieure. C'est le cas des thèmes de supplication et des demandes d'intercession, ou encore du ton hautement émotif, associé à un degré de lyrisme traduisant une dévotion personnelle, qui deviendra la

\footnotetext{
1 Mort autour de 40/66o. Voir 'Arafāt, "Ḥassān b. Thābit". Voir aussi Monroe, The Poetry, 368-373.

2 Voir Basset, "Kacb b. Zuhayr"; Stetkevych Pinckney, The Mantle odes, en particulier le chapitre 1: "Kacb Ibn Zuhayr and the Mantle of the Prophet" 1-69 et Stetkevych Pinckney, "Pre-Islamic Panegyric" 1-49.

3 Poète préislamique, voir Arazi, "al-Nābigha al-Dhubyānī".

4 Cette célèbre dāliyya fut intégrée par certains anthologues parmi les Múallaqāt.

5 Voir Zakī, Al-Madäih al-nabawiyya, et Zwettler, The Poet and the Prophet, 313-387.
} 
règle dans les poèmes post-classiques. Du point de vue stylistique, ces derniers se caractérisent par un emploi intensif du badī associé, depuis lâge classique, à l'hégémonie religieuse, culturelle et politique de l'islam. L'exemple le plus emblématique de cette production relativement tardive est sans nul doute le poème communément dénommé la Burda de Sharaf al-Dīn Abū 'Abd Allāh Muhammad b. Sa'īd al-Būṣīī̄ī (m. 694-96/1294-97) ${ }^{7}$. Suzanne P. Stetkevych a montré que léloge du Prophète puisait à diverses sources religieuses : le Coran, la Sìra, le hadīth et notamment les Shamä̉il de Tirmidhī (m. 278/892) réunissant des traditions sur les qualités physiques et morales du Prophète. S'y ajoute le concept de Lumière muhammadienne, développé plus tard sous le nom de Réalité muhammadienne (al-ḥaqĩqa l-muhammadiyya) à l'origine du monde, tout comme le Prophète, "Sceau des prophètes," intercède pour les hommes lors du Jugement dernier.

Toutefois, nombre d'éléments de ces éloges proviennent aussi de la tradition du madịh de cour existant depuis la Jāhiliyya. Poétisés et non narrativisés, tous ces éléments servent dans le cadre de la polémique contre les ennemis de l'islam. On assiste donc, selon cette chercheuse à une transformation d'une présentation prosaïque, historique et narrative en mythisation qui confère à ces matériaux une dimension métaphysique et métahistorique, cosmique et mythique.

Dans l'Occident musulman, le genre ne fut guère cultivé avant le $\mathrm{VI}^{\mathrm{e}} /$ XII ${ }^{\text {e }}$ siècle, même si la sīra du Prophète suscita l'intérêt des Andalous. Deux ouvrages furent d'une importance déterminante pour son développement: al-Shifā̉ fì l-ta'rīif bi-ḥuqūq l-Muștafāa, du Qāạī 'Iyāọ b. Mūsā (m. 544/1149) et le Raw ḍ al-unuf, glose de la sīra d'Ibn Hishām, d'Abū Zayd 'Abd al-Raḥmān b. 'Abd Allāh al-Suhaylī (m. 581/1185). Selon Maḥmūd Makkī, qui a retracé la genèse de ce genre poétique dans cette partie du Dār al-islām ${ }^{8}$, les premiers madāịh nabawìya andalous auraient été l'œuvre d'Ibn al-Sayyid al-Bațalyawsī (m. 521/1127), mais c'est surtout Muḥammad b. Mas'ūd b. Abī l-Khișāl ${ }^{9}$ (m. 540/1146) qui, avec un poème de 366 vers intitulé : Mírāj al-manāqib wa-minhāj al-ḥasab $a l$-thāqib, aurait donné un élan décisif à ce genre ${ }^{10}$. Ces poèmes exaltant le

6 Voir "al-Būșirī” 158-9.

7 Ce poème a fait l'objet d'une étude détaillée de la part de Pinckney Stetkevych, dans le chapitre 2 ("al-Bușinin and the dream of the Mantle") de son ouvrage The Mantle odes, 70-150.

8 Makkī, al-madāih al-nabawìya.

9 Juriste, traditionniste et lettré andalou, mort en 540/1146.

10 Ce poème évoque la généalogie du Prophète, sa biographie, les miracles qui lui sont attribués et les vertus de ses compagnons. Il est reproduit par Maqqarī dans Azhār al-riyād, avec le takhmīs composé par Abū 'Abd Allāh Muḥammad ibn al-Ḥasan al-Mursī (m. après 
voyage mystique sur la route du pèlerinage furent particulièrement populaires en al-Andalus. Makkī mentionne également les compositions de Muḥammad b. Muhạmmad Ibn al-Jannān al-Mursī (m. 646/1248), qui dut quitter Murcie pour Ceuta en 640, avant de s'établir à Bougie, ainsi que les compositions d'Ibrāhīm b. Sahl al-Ishbīlī (m. 649/1251 $)^{11}$ takhmissāt avec rime en 'à (sam'ā).

Il semble probable que ces compositions datant des $\mathrm{VI}^{\mathrm{e}} / \mathrm{XII}^{\mathrm{e}}$ et $\mathrm{VII} / \mathrm{e} / \mathrm{XII}^{\mathrm{e}}$ siècles aient profondément influencé les poètes ultérieurs et servi de matrice à leur production sur ce thème, même si, comme nous le verrons, un fait majeur, l'instauration et la généralisation de la célébration de la fête du Mawlid en Occident musulman, sera venu entretemps enrichir la thématique des poèmes d'éloge au Prophète ${ }^{12}$.

Notre étude se propose de se pencher sur les poèmes dédiés au Prophète (nabawiyyāt ou madāih nabawiyya) composés par le célèbre polygraphe grenadin de l'époque nașride Lisān al-Dīn Ibn al-Khāțîb (713-76/1313-74 ou 75) $)^{13}$ qui, pour certains, relèvent du sous-genre mawlidiyyāt. Nous procèderons à l'analyse de trois qașída-s emblématiques de cette veine ${ }^{14}$ : une dāliyya de 82 vers $^{15}$, une hăäiyya de 39 vers $^{16}$ et une bä'iyya de 54 vers $^{17}$.

679) (Maqqarī, Azhār al-riyāọ, 5 : 173-249). Sur L'auteur, Ibn Abī al-Khișāl, voir Maqqarī, Azhār al-riyāẹ, 5: 167-172. Celui-ci est aussi l'auteur de poèmes intitulés al-nabawiyyāt ainsi que de cinq thrènes du Prophète pastichant ceux de Hassān b. Thābit.

11 Deux de ses qașídas, en particulier, s'inscrivent dans ce genre. Chacune d'entre elles comprend 30 vers. La première est construite sur le mètre țawīl (rime en 'âa) et la seconde, composée juste avant la chute de Séville et appelant au jihād, sur le mètre kāmil (rime en $r \bar{\imath})$. Voir Ibn Sahl al-Ishbīlì, Dīwān, 207-212, pour la première, et 157-161, pour la seconde. Ibn Sahl est aussi l'auteur d'une takhmīsa avec rime en 'ā (sam‘ā) dans la même veine.

12 Voir sur l'histoire de cette célébration: Katz, The Birth of the Prophet.

13 Abū 'Abd Allāh Muhammad b. 'Abd Allāh b. Sacīd ibn 'Abd Allāh b. Sa'īd b. 'Alī b. Ahmad al-Salmānī al-Lawshī, plus connu sous le nom de Lisān al-Dīn Ibn al-Khațīb. Voir à son sujet : Vidal-Castro, "Ibn al-Khațīb, Lisān al-Dīn"; Knysh, "Ibn al-Khațīb" 358-371; Arié, L'Espagne musulmane; du même auteur, "Lisān al-Dīn Ibn al-Khațịb" 69-81; Tahtah, Al-ğurba wa-l-ḥanīn, 317-341; Abbādī, Mu'allafāt Lisān al-Dìn ibn al-Khațīb, 247-53; Rodríguez Gómez, Peláez, and Boloix Gallardo eds. Saber y poder en al-Andalus ; Santiago Simón, El polígrafo granadino Ibn al-Jațīb ; Tițwānī, Ibn al-Khațīb.

14 Il s'agit là d'une première étape de notre recherche et nous souhaitons, à plus long terme, analyser l'ensemble de ces poèmes et les comparer à ceux composés à l'occasion d'autres fêtes rituelles et, plus généralement, aux poèmes dits sulțanniyyāt de l'auteur.

15 Ce poème, sur le mètre țawìl, figure dans Maqqarī, Naf̣̆ al-Ṭîb, 6: 451-55, dans Ibn al-Khațīb, Ihāạta, 4 :392-96 et dans Ibn al-Khațīb, Dīwān, 1: 345-350.

16 Pour ce poème, sur le mètre kāmil, voir : Maqqarī, Nafḥ al-Ṭ̄̈b, $6: 449-51$; Ibn al-Khațīb, Dēwān, $1: 241-44$ et Ihăța, $4: 390-392$.

17 Pour ce poème, sur le mètre țawill, voir Maqqarī, Naf̣̣ al-Tīb, 6: 361-63, Ibn al-Khațīb, Dīwān, $1: 156-59 ;$ Ihạța, 4:467-70. 
Pour mettre en lumière les enjeux de ces textes, il nous faut en premier lieu évoquer la spécificité du contexte, tant historique que personnel, dans lequel ils virent le jour. Sur le plan historique, d'abord, la période est marquée par l'influence exercée sur le Royaume nasride de Grenade, pour le compte duquel travaillait Ibn al-Khatīb, par la dynastie mérinide ${ }^{18}$ (Banū Mārīn), qui règne alors sur le Maroc, et avec laquelle notre auteur entretint des relations très étroites. Lactivisme de cette dynastie dans le domaine religieux ne manqua pas, en effet, d'avoir des répercussions sur la production littéraire qui nous occupe.

Dépourvus, au départ, d'une idéologie religieuse, les Mérinides furent confrontés à un problème de légitimité. Pour se démarquer du mahdisme almohade et affirmer leur autonomie par rapport aux Hafșides au pouvoir à Tunis, ils adoptèrent une double stratégie. Ils encouragèrent d'abord le retour en force du malékisme, qui avait été marginalisé par le pouvoir almohade ${ }^{19}$. Dans le même temps, ils introduisirent dans leur état le système des médersas, qui s'était développé dans l'Orient sunnite dès le milieu du ve $/ \mathrm{XI}^{\mathrm{e}}$ siècle, faisant de ces écoles, toutes officielles et étatiques, les rouages de transmission de leur propagande. Par ailleurs, ils veillèrent particulièrement à la promotion de leur réputation de piété et d'équité et à l'affirmation de leur engagement dans le jihād. Poussé par son aspiration au califat, Abū 'Inān (749-759/ 1348-1358) n'épargna guère ses efforts pour paraître digne de cette institution, allant jusqu'à faire dire à ses biographes qu'il « se comportait envers ses sujets comme le Prophète ${ }^{20}$. Mais, surtout, ces souverains assurèrent la promotion d'un chérifisme servant leur cause, rompant ainsi avec la vision qui avait été celle des périodes précédentes, durant lesquelles la généalogie chérifienne, toujours associée au Mahdisme, était l'objet d'une suspicion tenace ${ }^{21}$. La chercheuse marocaine Halima Ferhat résume en une formule le tournant pris sous les Mérinides : « c'est la dynastie des Mérinides qui transforme le chérifisme en fond de commerce $»^{22}$.

Les sultans mérinides s'inspirèrent en la matière de l'exemple d'Abū l-Qāsim al-'Azafĩ qui s'était révolté contre les Ḥafșides en 647/1249 à Ceuta en s'appuyant sur le chérifisme, ce qui lui avait permis de fonder une dynastie

\footnotetext{
18 Cette dynastie commença à régner sur le Maghrib occidental (Maroc) à compter du milieu du VII $\mathrm{e} / \mathrm{XIII}$ e siècle. Voir Shatzmiller, "Marīnides".

19 Voir à ce sujet: Kably, Société, pouvoir et religion, 279-314, et Buresi et Ghouirgate, Histoire du Maghreb.

$20 \quad$ Kably, Société, pouvoir et religion, 291.

21 On se souvient qu'Ibn Tūmart revendiquait une généalogie chérifenne.

22 Ferhat, "Chérifisme" 473-482.
} 
qui allait régner durant près d'un siècle sur la ville. Il avait, la même année, instauré la fête du Mawlid, jusqu'alors inconnue au Maroc, déclarant vouloir contrer ainsi l'influence des fêtes chrétiennes. Cette alliance avec les chérifs avait aussi tout, semble-t-il, d'une « démarcation idéologique ${ }^{23}$.

Abū l-Qāsim suivait en cela l'exemple de son père, Abū l-'Abbās al-'Azafî24, auteur d'un ouvrage, al-durr al-munazzam fì mawlid al-nabì al-mu'azzamª considéré comme fondateur du culte du Prophète dans la région, mais aussi à visée polémique, puisqu'il s'agissait, avec cette fête du Mawlid, de concurrencer le Noël chrétien et d'autres fêtes populaires. Ceuta, qui avait accueilli de nombreux Andalous, était à l'époque un brillant centre de savoir ${ }^{26}$. C'est là qu'avaient été rédigés, dès le XII ${ }^{\mathrm{e}}$ siècle, plusieurs ouvrages importants sur le Prophète, dont le très célèbre Kitāb al-shifä’ du Qāḍī 'Iyāạ que nous avons évoqué plus haut ${ }^{27}$.

Pour promouvoir le chérifisme, les Mérinides se tournèrent à plusieurs reprises vers les chérifs du Hijāz ${ }^{28}$. Halima Ferhat montre que, suite à ces initiatives, de nombreux chérifs arrivèrent de Médine et d'Irak, qui se virent accorder par le pouvoir, des rentes et des dispenses fiscales. A l'occasion de la fête du Mawlid, ces chérifs recevaient de nombreux présents et des vêtements d'apparat. Ainsi, sous Abū 'Inān, chaque chérif percevait une rente annuelle de 100 dinars or ${ }^{29}$. Les souverains finirent néanmoins par s'intéresser davantage aux chérifs du Maroc, qui pouvaient s'intégrer plus facilement au système ${ }^{30}$. Jusqu'au XIV ${ }^{\mathrm{e}}$ siècle, les soufis restèrent indifférents à cette promotion des chérifs car, pour eux, le mouvement était « politique et perçu comme tel ${ }^{31}$.

En 691/1292, les Mérinides décrétèrent à leur tour le Mawlid fête officielle et publique dans leurs états, prenant en charge l'ensemble des frais afférents à cette célébration. C'est en cette occasion qu'étaient récités les poèmes dits mawlidiyyāt, auxquels était intégré un éloge du souverain ${ }^{32}$. On note que, dans toutes ces manifestations, un lien était soigneusement entretenu par

23 Kably, Société, pouvoir et religion, 286.

24 Abū l-Abbās Aḥmad ibn Muḥammad ibn al-Ḥusayn Ibn Abī 'Azafa l-Lakhmī, amīr de la ville de Ceuta (m. 633).

25 Voir Fernando De la Granja, "Las fiestas cristianas".

26 Ferhat, "Sabta", Ferhat, Sabta des origines au XIVe siècle.

27 M. 544/1149, voir Talbi, "Iyāẹ b. Mūsā".

28 Cette ouverture sur le Hedjaz se produisit à deux reprises : en 703/1303 et 736/1335. Voir à ce sujet Kably, Société, pouvoir et religion, 110-112 et 292.

29 Ferhat, "Chérifisme" 478-479.

3o Voir Kably, Société, pouvoir et religion, 293.

31 Ferhat, "Chérifisme" 480.

32 Voir aussi : Salmi, "Le genre des poèmes de Nativité". 
leurs instigateurs avec la célèbre Burda d'al-Būṣīīi. Selon Maḥmūd 'Alī Makkī, c'est au cours du VIII ${ }^{\mathrm{e}} / \mathrm{XIV}^{\mathrm{e}}$ siècle que le Mawlid devint l'une des fêtes les plus importantes au Maghreb, notamment sous l'égide du sultan Abū Ḥammū Mūsā b. Yūsuf al-Zayyānīī3 ${ }^{3}$, roi de Tlemcen, aucun poète ne pouvant alors faire l'impasse sur ce genre de composition.

Le succès de la célébration du Mawlid fut très clairement l'un des facteurs de la diffusion du culte du Prophète. Les deux phénomènes, la montée en puissance du chérifisme et la généralisation de la célébration de l'anniversaire de la naissance du Prophète, contribuèrent à ériger le respect et l'amour des ahl al-bayt en impératif social.

Cependant, comme l'a montré Halima Ferhat, le développement de ce culte fut aussi favorisé par l'encouragement du pèlerinage à La Mecque ${ }^{34}$. Celui-ci fut, en particulier, impulsé par un homme, Abū Muhammad Șāliḥ ${ }^{35}$, vénéré par beaucoup comme un «saint ». Originaire de Safi, il conçut une organisation rigoureuse du voyage vers les Lieux saints à l'intention des pèlerins marocains. La caravane, nommée rakb al-hajj, partait du ribāt de Safi. Les pèlerins devaient se conformer à des règles très strictes : port du chapelet, d'une gourde, d'un bâton, psalmodies de prières et de chants durant le voyage. Des étapes étaient prévues tout au long du parcours. Les Maghrébins furent de ce fait de plus en plus nombreux à Médine, et la visite du tombeau devint aussi importante à leurs yeux que le séjour à La Mecque. Cependant, pour tous ceux qui ne pouvaient pas partir, une tradition, remontant, d'après $\mathrm{H}$. Ferhat, au moins aux Almoravides, consistait à envoyer des messages à Médine (dit hijāziyyāt). Certains de ceux-ci, rédigés par des personnalités de premier ordre, tel le Qāạī 'Iyāọ, Ibn Abī l-Khișāl, Abū l-Qāsim al-'Azafì et Ibn Khalas jouissaient d'une grande notoriété. A l'époque nașride, ces lettres pouvaient prendre la forme de suppliques priant Dieu d'épargner et de sauver le Royaume de Grenade. Ibn al-Khatîb lui-même se plia à cet usage ${ }^{36}$.

33 Makkī, al-madāịh al-nabawiyya, 127-128. Membre de la dynastie des Banū 'Abd al-Wād, il régna entre $760 / 1359$ et 791/1389. Fin lettré, il est lui-même l'auteur de mawlidiyyāt, consignées dans son ouvrage Wāsițat al-sulūk. Makkī cite un passage du Nazm al-durar wa-l-'iqyān fì bayān sharaf Ban̄̄ Zayyān, d'Abū 'Abd Allāh al-Tanasī l-Tilimsānī qui décrit le faste de la fête du Mawlid à la cour de ce sultan. Sur cette dynastie, voir Marçais, "Abd al-Wādides".

34 Ferhat, "Le culte du Prophète" 89-97.

35 M. 631/1234. Voir : Gril, "Abū Muhammad Șāliḥ".

36 Voir Addas, La maison muhammadienne, 27. 
Si les madāih nabawiyya relèvent de la poésie de circonstance destinée à être déclamée dans le cadre des manifestations officielles, que ce soit à la cour des Nasrides ou à celle des Mérinides, entretenant de ce fait une étroite parenté avec le genre du panégyrique, dans lequel Ibn al-Khațib s'est illustré tout au long de sa vie ${ }^{37}$, il n'en reste pas moins que les trois poèmes que nous nous proposons d'analyser portent la marque du contexte personnel dans lequel se trouvait leur auteur au moment de leur composition et du tournant pris par sa vie à cette période. Les trois odes furent, en effet, composées lors de son séjour au Maghreb, entre $760 / 136$ o et 763-4/1363.

Destitué en 1360, le souverain nasride Muḥammad v s'était réfugié à la cour mérinide de Fès ${ }^{38}$. Ibn al-Khațîb put bientôt à son tour s'installer au Maroc, où il bénéficia de la protection du Mérinide Abū Sālim Ibrāhīm, qui lui octroya une généreuse pension ${ }^{39}$. Toutefois, plutôt que de rejoindre Fès, il préféra voyager à travers le pays et finit par s'établir à Salé, ville dans laquelle vivaient de nombreux mystiques ${ }^{40}$ et où il demeura presque deux ans ${ }^{41}$. Le climat particulier régnant dans cette ville exerça sur lui une forte influence et l'on assista alors à une montée en puissance de sa poésie religieuse ${ }^{42}$. Il s'agit donc là d'une période très importante pour sa production poétique et intellectuelle. Le décès de son épouse (en 762/1361) qui, selon ses biographes, le marqua profondément, accentua encore cette mutation. Ibn al-Khațîb ne quitta Salé qu'à regret lorsque, Muhammad v ayant recouvré son trône (en $763 / 1362$ ), il fut contraint de le rejoindre à Grenade ${ }^{43}$.

37 Comme c'est le cas pour la grande majorité des poètes de l'époque, le panégyrique constitue le genre le plus cultivé par Ibn al-Khațīb et occupe la plus grande partie de son Dīwān.

38 Sur les détails de ces événements politiques, voir Arié, L’Espagne musulmane, 106-118.

39 Cette pension se montait à 500 dinars d'argent mensuels : voir Knysh, "Ibn al-Khațîb" 359.

40 Le plus célèbre de ces soufis était à l'époque Ibn 'Āshir. Voir: Faure, "Ibn 'Āshir".

41 Voir Ferhat, "Salā". La cité avait été prise par les Castillans en 658/126o qui l'avaient saccagée en massacrant une partie de la population. Le Mérinide Abū Yūsuf (656-85/1258-86) se porta au secours de la ville et participa à l'édification des remparts qui n'avaient pas été relevés par les Almohades (Voir Ibn 'Idhārī, Kitāb al-Bayān, 418-425 et A. Huici-Miranda, La Toma de Salé).

42 La prolifique bibliographie d'Ibn al-Khațîb compte un ouvrage partiellement consacré au soufisme : Rawdat al-tárîf bi-l-hubb al-sharïf. Néanmoins, pour qualifier sa relation à cette mouvance, il faut plutôt parler d'attirance que d'adhésion, l'homme fort de Grenade n'ayant jamais renoncé au faste et aux privilèges de la vie de cour.

Voir l'introduction au Dēwān Ibn al-Khațīb de Muḥammad Miftāḥ. 


\section{$3 \quad$ Analyse des trois poèmes}

\subsection{Les circonstances de leur composition}

La hẳityya n'est pas datée et nous ignorons pour quel souverain elle fut composée. Néanmoins, dans son ouvrage al-Ihạțta fi akhbār Gharnāța, Ibn al-Khațīb précise qu'il s'agit de l'une de ses premières compositions sur ce thème ( $\min$ awwaliyyāt nazmī fì dhālika l-gharad $)^{44}$.

La dāliyy $a^{45}$, quant à elle, est présentée dans le Dīwān comme une qașìda mîlādiyya adressée par l'auteur depuis Salé à Fès. Dans al-Ihạtț $\bar{a}^{46}$, une indication supplémentaire est donnée : l'auteur nous informe qu'il a déclamé cette ode devant le «sultan du Maghreb durant la nuit de la célébration de la naissance du Prophète de l'an 763 » $(1362)^{47}$. Le destinataire du poème est le sultan mérinide Abū Sālim Ibrāhīm, qui avait accueilli en exil le souverain nasride Muhammad $v$ et son vizir après le coup d'état de $760 / 1359$.

Enfin, Lisān al-Dīn précise que la $b \bar{a} \mathfrak{y} y a$ figurait en tête d'une épître écrite au nom du sultan nasride Muḥammad v al-Ghanī bi-llāh et adressée au mausolée du prophète (ilā l-darịh al-nabawī l-karìm) en $762^{48}$.

Ces données attestent donc qu'au moins les deux derniers poèmes ont été composés durant le séjour d'Ibn al-Khațîb à Salé.

\subsection{Structure des poèmes}

Dans son ouvrage intitulé The Mantle Odes ${ }^{49}$, Suzanne Pinckney Stetkevych distingue deux types de poèmes d'éloge au Prophète : le premier rassemble des odes dites de « supplication », structurées selon le modèle tripartite du panégyrique en vigueur depuis l'Antéislam. Celles-ci se composent d'un nasïb permettant au poète d'évoquer une passion profane dont il a décidé de se détourner, d'un rahīl à caractère initiatique marquant la rupture entre les anciennes allégeances du poète et le cheminement vers un nouveau pôle, sorte d'acte de contrition dans lequel le poète exprime les regrets quant à sa conduite passée et sa soumission à un ordre nouveau et, enfin, d'un éloge intimement mêlé à la supplication. Ce type de poème est représenté, en particulier, par les deux célèbres Burda-s, celle de Ka‘b b. Zuhayr et celle d'al-Būṣīin que cette chercheuse

\footnotetext{
44 Ibn al-Khațīb, al-Ihạța, 4:39o.

45 Ibn al-Khațīb, Dīwān, $1: 345^{-5}$ o.

46 Ibn al-Khațīb, al-Ihạta $4: 392$.

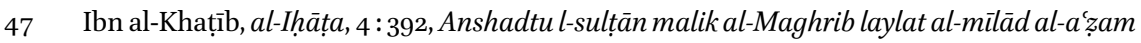
min 'ām thalāthata wa-sittīn wa-sab'imiatin hādhihi l-qașīda. On trouve la même précision dans le Nafḥ, qui reprend al-Ihāța.

48 Ibn al-Khațīb, Dīwān, $1: 157$.

49 S. P. Stetkevych, The Mantle odes.
} 
a analysées en détail. Le second type est représenté par les poèmes relevant du courant soufi, dont le meilleur représentant, à l'époque post-classique, est sans aucun doute l'Égyptien Ibn al-Fāriḍ ${ }^{50}$. Ces poèmes de ghazal mystique sont d'un bout à l'autre dominés par un lyrisme dévotionnel que l'on peut qualifier de «statique», dans lequel le poète est paralysé par le désir qui le submerge. Ils se caractérisent également, comme l'a montré Jaroslav Stetkevych ${ }^{51}$, par une extension du nasīb à l'ensemble du poème, la qașída prenant alors la forme d'un long nasī $b^{52}$.

A laquelle de ces deux catégories appartiennent les madāih d'Ibn al-Khațib sur lesquels nous nous penchons? Que pouvons-nous dire de leur structure? Et, d'abord, quelle place y est accordée à l'éloge du Prophète ? Dans la dāliyya, celui-ci n'occupe qu'une partie relativement modeste, bien que centrale, se réduisant à une séquence de 17 vers (v. 42-59) sur un total de 82 vers. C'est en outre le seul des trois poèmes à se conclure par un panégyrique de facture classique, adressé au sultan mérinide. Dans la hạäiyya, l'éloge du Prophète ne débute qu'au vers 19, tandis que, dans la bẳiyya, les évocations de celui-ci sont disséminées à partir du v. $18^{53}$.

Des trois odes, c'est la hăàyya qui présente la structure se rapprochant le plus de celle, tripartite, de la qașìda classique. Elle débute en effet par un nasīb de 10 vers, de type talalì, qui se clôt sur une mise en exergue du nom manäzil («demeures »), particulièrement représentatif de ces prologues focalisés sur l'évocation d'une demeure disparue :

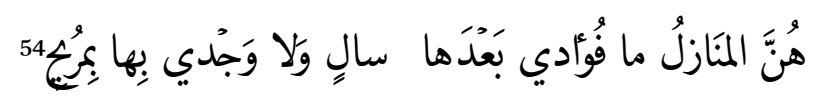

Commence ensuite la deuxième séquence, que nous pouvons identifier comme un raḥil (v. 11-19). D'emblée, celui-ci est présenté comme imaginé, réalisé uniquement, en pensée (v. 11). Pourtant, dès le vers 13, le poète, qui décrit ce périple nocturne (suran) en utilisant des verbes à l'accompli, semble rechercher un effet de réel qui bâriqin les frontières entre rêve et réalité :

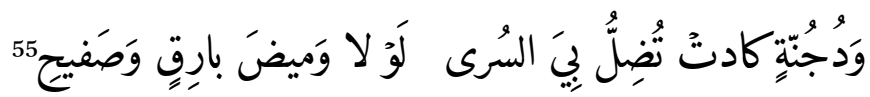

$50 \quad$ M. 632/1235. Voir Nicholson et Pedersen, "Ibn al-Fāriḍ".

51 Stetkevych, The Zephyrs of Najd, 89.

$5^{2}$ Stetkevych, The Zephyrs of Najd, 79-102.

53 Il s'agit des v. 18 et 19, 33, puis $36-54$.

54 Hä̀iyya, v. 10 : "Ce sont les demeures : jamais mon cœur ne pourra se consoler de leur perte ni la passion que j'éprouve pour elles s'apaiser".

55 Hā'iyya, v. 13: "C'était une nuit très sombre et, n'était l'éclat lumineux d'un éclair et de la lame d'une épée, le voyage nocturne aurait pu me faire perdre tous mes repères". 
Nous retrouvons, dans cette séquence, quelques uns des motifs les plus fréquemment utilisés pour évoquer le surā: le scintillement tremblant des étoiles, comparé à celui de pièces de monnaie dans la main d'un avare (v. 14), l'assimilation de l'obscurité ambiante à une mer sans fond (v. 15) et l'évocation de l'aurore sous la forme d'une main effleurant le visage du matin (v. 16). Ce périple se termine par l'arrivée à Médine, arrivée dont le statut est tout aussi ambigu (v. 19).

Enfin, une troisième et dernière séquence est consacrée à l'éloge du Prophète, séquence dans laquelle, comme nous le verrons, le sujet intervient à plusieurs reprises.

La ḍāliyya présente une structure plus complexe. En effet, son nasīb, plus long (23 vers), inclut deux micro-récits ayant pour acteurs des éléments naturels et qui détournent un moment le destinataire de l'attention portée au sujet élégiaque. Ibn al-Khațīb se conforme ainsi à la tradition poétique andalouse qui substituait régulièrement au mațla talalī une séquence donnant à voir une scène printanière ou une évocation florale narrativisée.

Le premier micro-récit (v. 2-6) met en scène un éclair et un nuage, tous deux personnifiés. Le premier, du genre masculin (wamīẹ), est investi du rôle du séducteur, tandis que le nuage, du genre féminin en arabe (ghamāma ou bahriyya), se voit confier celui de la belle courtisée ${ }^{56}$ :

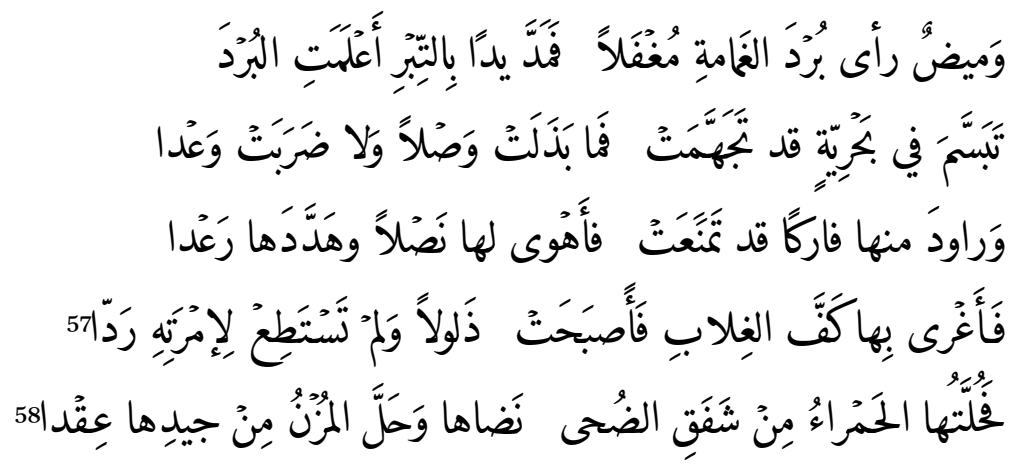

$5^{6}$ C'est la raison pour laquelle nous avons opté, dans notre traduction et pour davantage de lisibilité, pour l'emploi du nom "nue".

57 Ce vers ne figure pas dans l'I 1 ăța.

$5^{8}$ "Voyant le manteau de la nue dépourvu de tout ornement, un scintillant éclair tendit une main poudrée d'or qui marqua le manteau / Il adressa un sourire à une nue renfrognée, mais celle-ci refusa toute union et s'abstint de toute promesse / Il força alors à se donner une épouse pleine de haine qui se refusait à lui, lui décochant une flèche et la menaçant du fracas de son tonnerre / Puis il activa à son encontre la main de la domination qui la rendit docile, incapable de contrer son autorité / Il la dépouilla alors de son vêtement pourpre [taillé] dans le rougeoiement du soleil matinal, tandis que le nuage chargé de pluie dénouait le collier de son cou". 
L'entreprise de séduction comporte plusieurs phases; dans un premier temps, l'éclair tente d'amadouer la nue en brochant d'or son «manteau ». Mais il se heurte à la résistance de la belle qui arbore un visage renfrogné (tajahhamat) et ne veut pas entendre parler d'union. La seconde phase de l'entreprise s'apparente à un processus d'intimidation, l'éclair lançant ses flèches sur la récalcitrante et la menaçant de son tonnerre. On passe alors de la séduction à une lutte qui se traduit par une agression et aboutit à la soumission totale de la nuée. La seule façon d'accéder à l'objet de son désir est donc, pour l'éclair, le recours à la violence. Notons que cette méthode est en totale contradiction avec celles de l'amant 'udhrite, dont les seules armes sont la constance et l'abnégation, et du mystique aspirant à l'union avec son aimé. Le dénouement de cet épisode orageux n'en est pas moins heureux, puisque le substantif muzn, qui apparaît dans le dernier vers du passage, indique l'arrivée de la pluie toujours perçue, dans l'imaginaire arabe, comme une bénédiction. Les images déployées dans ces vers font écho aux représentations favorites des poètes paysagers andalous, tel Ibn Khafāja ${ }^{59}$, qui utilisait fréquemment le procédé consistant à narrativiser l'arrivée de la pluie.

A partir du vers 7 , un second micro-récit prend le relais, dont l'acteur principal est de nouveau un éclair (barq et wamīẹ). Son éclat est comparé à la lueur d'un briquet allumé par la main d'un veilleur frigorifié. Il s'agit là d'une comparaison qui, avec des variantes, est présente dans la poésie arabe depuis les temps les plus anciens. La scène qui conclut le micro-récit (v. 9-10) nous montre l'averse, déclenchée par l'éclair, métamorphoser la terre en jardin. Elle aussi se situe en droite ligne des représentations paysagères développées par les Andalous et, en particulier, par Ibn Khafāja. Cette fois, c'est le substantif bilād qui est utilisé pour nommer la demeure tant aimée par le sujet, terme assez vague pour entretenir, comme nous le verrons, une grande ambiguïté quant à sa nature et à sa localisation ${ }^{60}$.

La séquence du rahīl commence au vers 24 , avec le participe murtahil introduit par un wāw rubba, dont la fonction consiste à marquer la transition entre deux parties de la qașída. Cette fois, et à la différence de la hä̉yya il est clair que le périple est entrepris par d'autres que le sujet, contraint de renoncer à son projet, et qu'il s'agit donc, en quelque sorte, d'un voyage «par procuration». A partir du vers 38 débute la partie consacrée à léloge du Prophète. Cependant, au sein de cet éloge s'insèrent huit vers focalisés sur le sujet. Ceux-ci sont suivis par une courte séquence (4 vers) évoquant la naissance du Prophète. Enfin, le poème se termine par un panégyrique (13 vers) adressé au mérinide Abū

$59 \quad$ Mort 533/1138.

6o Hä̀ìya, v. 11. 
Sālim. La structure de cette dāliyya peut donc être qualifiée de quadripartite, puisqu'elle renferme deux éloges, le premier destiné au Prophète et le second au protecteur du poète.

Qu'en est-il, enfin, de la structure de la bä̈ryya ? Notons d'abord que son nasīb est plus bref que celui des deux autres odes ( 7 vers) et qu'il met avant tout l'accent sur la distance physique séparant le sujet et le lieu auquel celui-ci se sent lié. Ce dernier est désigné par le pluriel ma'ālim ( «signes », « marques »), autre nom du répertoire talalī. Le huitième vers, avec l'entrée en scène du chamelier et de ses bêtes, semble marquer le début du rahīl:

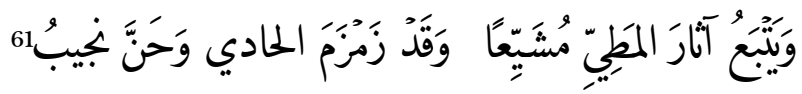

La mention de la caravane de pèlerins (rikāb al-hajj, v. 10) précise la nature du périple évoqué. Cependant, la suite du poème est un ensemble assez hétéroclite, où alternent les confessions d'un sujet révélant son incapacité à effectuer ce voyage et les invocations du Prophète. Cette spécificité tient sans aucun doute au fait que, comme nous l'avons dit, ce poème constituait l'en-tête d'une lettre rédigée au nom du nașride al-Ghanībillāh, lettre relevant d'un genre ayant notamment comme fonction de compenser l'impossibilité d'accomplir le hajj. Tout aussi spécifique est la manière dont se conclut le poème, puisque la dernière partie de la qașída (v. 38-54) est dédiée à l'évocation des efforts accomplis par le souverain nașride pour défendre l'islam et réduire ses ennemis.

Les trois poèmes que nous avons sélectionnés présentent donc des structures assez différentes. Un point commun les réunit néanmoins : la multiplicité des interventions du sujet lyrique qui leur confèrent une tonalité particulièrement élégiaque.

\subsection{Deux pôles}

En effet, ces poèmes sont organisés autour de deux pôles, à savoir le sujet lyrique, d'une part, et l'objet de sa dévotion, le Prophète, d'autre part. Or l'espace occupé par le premier s'y avère proportionnellement plus important que celui dévolu au second, au point que l'équilibre entre les deux pôles s'en trouve souvent rompu. Cependant, le sujet mis en place par le poète se caractérise par son caractère foncièrement hétéronome : contrecarré par de nombreux obstacles, il est, comme nous allons le voir, condamné à l'inaction.

Dans un premier temps, nous nous intéresserons aux séquences focalisées sur le pôle «sujet», essentiellement localisées dans la première partie des

$61 B \bar{a}^{\prime}$ yya , v. 8: "Et il suit les traces des montures brûlant du désir de les rejoindre, [guidé par] les modulations du chamelier et le gémissement de la noble chamelle". 
qașidas. C'est là aussi que se met en place une atmosphère « arabique », caractéristique du style des madāih nabawiyya.

\subsection{Une atmosphère arabique}

Les éléments paysagers émaillant les trois odes sont, en effet, tous en relation avec un contexte désertique. Et une atmosphère arabique est créée dès les premiers vers. Dans la dāliyya, le Najd est cité à deux reprises dans le premier vers (najdiyyan et najdan). Si, dans la bä̉izya, cette atmosphère arabique est plus discrète, la hăàyya fait, quant à elle, deux fois référence au parfum de l'armoise du Hijāz ${ }^{62}$ porté par le vent (v. $2:$ shịh al-Hijāz et v. $3:$ shịh), tandis que le nom falät (v. 3) désigne sans ambiguïté un espace désertique.

L'utilisation de toponymes reliés au pèlerinage constitue, par ailleurs, un signe d'appartenance au genre madä ĭh nabawiyya. Cette tradition, qui permet de créer une atmosphère spirituelle, remonte à al-Sharîf al-Raḍi (m. 406/1o16) et à son élève Mihyār al-Daylamī (m. 428/1037). Elle s'est ensuite particulièrement développée dans la poésie soufie.

Néanmoins, cet espace arabique, dont le Najd est le symbole le plus marquant, se caractérise par une absence-présence. En effet, le sujet insiste avant tout sur la distance qui le sépare de ces lieux évoqués avec tant de passion. Ainsi, le premier vers de la bä’iyya est construit sur l'opposition entre la proximité désirée et la distance avérée, même si le désir est capable d'annuler, dans une certaine mesure, cette distance:

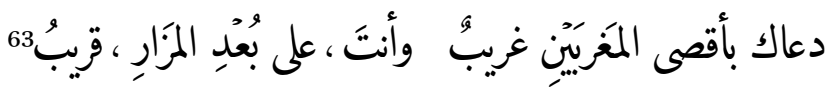

Ce motif de la distance et de l'éloignement est, notons-le, consubstantiel à la production poétique andalouse. Nombreux sont en effet les lettrés de ce territoire à avoir exprimé le sentiment douloureux de vivre à la périphérie du $D \bar{a} r$ al-Islām, très loin du Centre, de l'Orient, d'où cette familiarité avec la notion de gharāba, véritable leitmotiv de cette production poétique ${ }^{64}$.

Ce motif ressurgit plus loin dans la $b \vec{a}$ 'iyya: faute d'être en capacité de rejoindre ces terres désirées, le sujet espère voir ces dernières se rapprocher de lui :

62 Si cette plante, caractéristique du biotope désertique, pousse partout dans le monde arabe et au Maroc, le poète prend le soin de préciser sa provenance par une annexion.

$63 B \bar{a} \bar{y} y a$, v. 1: “Depuis l'extrême Occident, un étranger t'a invoqué, toi si proche malgré la distance qui nous sépare de ton tombeau".

64 Dans une autre qașida mawlidiyya, le lieu cristallisant le désir du sujet est, dès le premier vers, spécifié comme lointain : wa-l-diyāru nawāzị̣ū (Ibn al-Khațīb, Dīwān, 224, v. 1). 


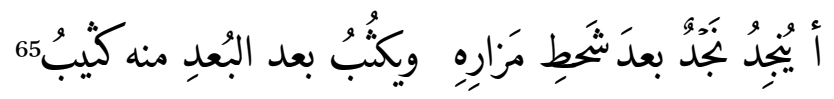

\subsection{Le déclenchement du désir}

Le sujet mis en place dans les trois poèmes peut avant tout être caractérisé comme un être désirant. Le déclenchement de son désir se produit au tout début du poème, suite à l'intervention d'un élément naturel. Dans la poésie arabe, deux motifs sont traditionnellement investis, dans le prologue (nasib), de la fonction d'éveiller la nostalgie et/ou le désir du sujet: l'éclair et la brise parfumée.

C'est le premier qui est convoqué dans la dāliyya. Si le terme le désignant (wamị̂d) n'apparaît qu'en incipit du deuxième vers, il est néanmoins le sujet grammatical du verbe qui ouvre le poème (ta'allaqa). Le sujet lyrique, quant à lui, prend la place du complément (adhkaranī), ce qui le place d'emblée en position de sujet hétéronome. Cette hétéronomie est réitérée dans le second hémistiche. Le désir (shawq / wajd) qui s'empare du sujet confère au prologue une tonalité élégiaque qui dominera l'ensemble du poème :

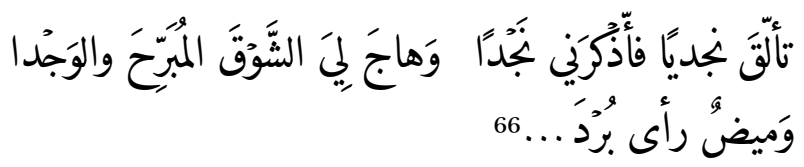

Dans la hăàyya, c'est le vent parfumé qui remplit cet office:

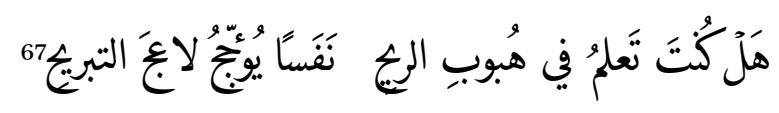

$\mathrm{Si}$, dans ce vers, le sujet interpelle un interlocuteur, il semble bien, qu'en réalité, il s'adresse à lui-même.

En revanche, le sujet de la $b \bar{a}$ iyya, qualifié d'étranger (gharīb) dans le premier vers, est plus actif puisque c'est lui qui prend l'initiative d'interpeller des éléments naturels, la lune et le soleil, et les charge de transmettre son salut à l'objet de son désir :

$65 B \bar{a}^{\prime} \bar{y} y a$, v. 14 : "Se peut-il que le Najd me vienne en aide et se rapproche, [pour annuler] la distance [qui me sépare] de son tombeau, et que la dune fasse de même ?".

$66 D a \bar{l}(\grave{y} y a$, v. 1 et 2 : "En Provenance du Najd, la lueur d'un éclair a illuminé [le ciel] et m’a rappelé le Najd, réveillant en moi un douloureux désir et une violente passion".

$67 H \bar{a}$ 'à $y$, v. 1 : "Reconnaissais-tu, dans les rafales du vent, un souffle réveillant la flamme de l'ardent désir ?" 


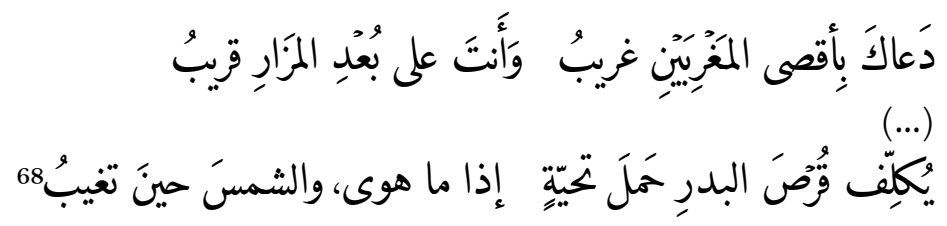

Le sujet, dont le désir s'est réveillé, se déclare dévoré par une passion brûlante et nombreux sont les lexèmes dénotant cette dernière dans les trois poèmes: wajd, d'abord, installé dans la dāliyya à la rime du premier vers et qualifié, dans

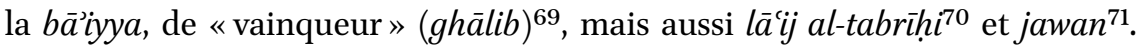
Les motifs traduisant cette passion dévorante ne diffèrent guère de ceux en usage dans la poésie amoureuse 'udhrite. L'amant, qui entretient une relation exclusive avec son aimé, souffre du mal d'amour et d'une soif inextinguible que seul celui-ci est susceptible de guérir : il est donc à la fois la source de ses souffrances et son seul espoir de guérison, de rédemption :
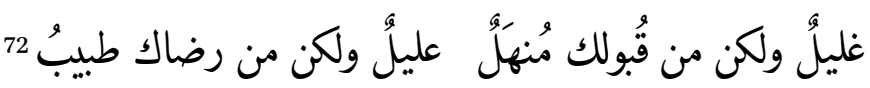

De la même façon, quand il s'agit de rendre compte du vertige dans lequel le plonge cette passion, les images convoquées sont très proches de celles de la poésie bachique. En effet, le verbe rannaha sert aussi à décrire les effets de l'alcool, tandis que le motif du rameau fléchissant sous l'action de la brise est omniprésent lorsqu'il s'agit de représenter l'ivresse et le plaisir :

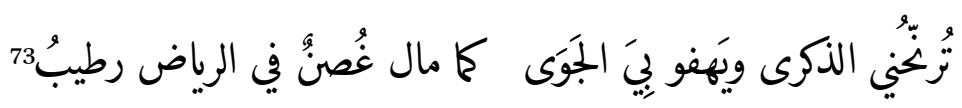

Notons que, dans ce dernier vers, le sujet, représenté par des pronoms affixes compléments, est montré comme étant le jouet de ses affects et privé de toute autonomie.

$68 B \bar{a} \bar{a} y a$, v.1 et 3 : “Depuis l'extrême Occident, un étranger t’a invoqué, toi si proche malgré la distance qui nous sépare de ton tombeau / Il charge le disque de la pleine lune, à l'heure de son couchant, et le soleil, lorsqu'il décline, de transmettre un salut".

$69 B \bar{a} ' \bar{y} y$, v. 24.

$70 \quad H \bar{a} ' \bar{y} y$, v.1.

$71 B \bar{a} \bar{y} y a$, v. 23.

$72 B \bar{a}^{\prime} \bar{y} y a$, v. 12 : "Assoiffé, mais [trouvant] en ton agrément une source; malade, mais [trouvant] en ta satisfaction le médecin [capable de me soigner]".

$73 B \bar{a} \bar{y} y a$, v. 23: "Le souvenir m'étourdit et la passion m'emporte, tel un rameau humide ployant dans un jardin". 


\subsection{L'expression de la passion}

Comme c'est le cas dans la poésie mystique, on retrouve, dans l'expression de la passion éprouvée par le sujet, les motifs et le style caractéristiques du ghazal 'udhri ${ }^{74}$.

Dans la dāliyya, le poète consacre une séquence conséquente à cette expression (v.15-23), dans laquelle figure expressément, d'ailleurs, l'expression al-hawā al-'udhrī. Le sujet s'y représente en esclave de l'amour ('abd):

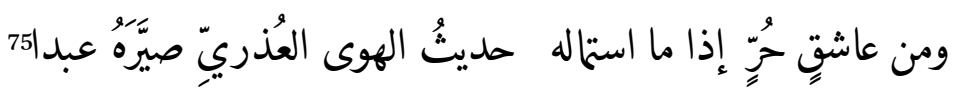

L'ethos de l'amant courtois est complété dans les vers suivants (v. 17-18), qui mentionnent la fidélité aux engagements (li-l-'ahdi ḥâfiż), la constance (șabūr), mais aussi la transformation physique provoquée par l'absence et le désir, muant un roc solide en un être faible et émacié (v. 21):

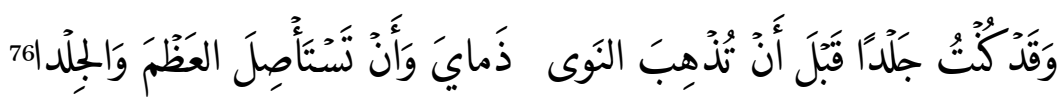

Le sujet décrit ensuite en détail les larmes alimentées par sa passion inassouvie (v. 22-24).

Dans la $h \bar{a}^{\prime} \bar{y} y$, le poète introduit, au vers 4, le motif de la colombe, désignée par une métonymie (khadībat al-minqār):

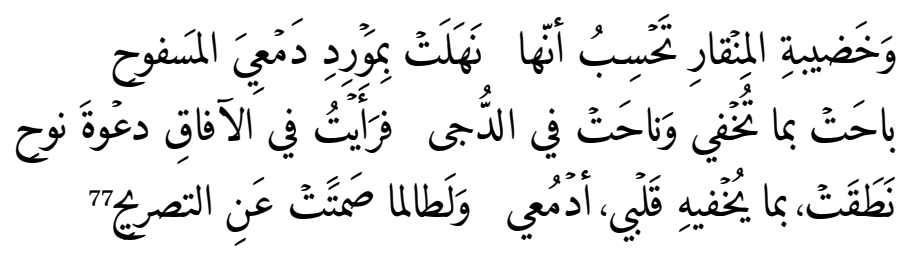

Cet oiseau, dont le roucoulement monotone évoque, dans les compositions élégiaques, le mal d'amour, est traditionnellement montré en empathie avec le sujet amoureux.

74 Cette appellation désigne la poésie amoureuse dite "courtoise" ou platonique, focalisée sur l'expression d'un amour unique et malheureux qui consume l'amant.

75 Dāliyya, v. 15: "D'un amant libre, le discours de la passion platonique a fait, après l'avoir amadoué, un esclave".

76 Dāliyya, v. 21 : "J'étais inébranlable avant que la distance vienne emporter ce qui me restait de vie et m'arracher la peau et les os".

77 Hä̀yya, v. 4-6: "On dirait que [la colombe] au bec comme] teinté de rouge s'est abreuvée à la source du flot de mes larmes/ Elle a révélé ses secrets et s'est lamentée dans les ténèbres de la nuit; et j'ai vu, à l'horizon, l'appel de Noé /Mes pleurs ont révélé ce que mon cœur cachait, après avoir longtemps préféré se taire". 
Dans la $b \bar{a} i \dot{y} y a$, un paroxysme dans l'expression de cette passion brûlante est atteint lorsque le poète fait appel à deux éléments, l'Eau et le Feu, lesquels sont communément convoqués, dans la poésie amoureuse, pour décrire les manifestations du mal d'amour enduré par l'amant. Sont alors évoqués le feu intérieur qui le consume et les flots de larmes qui, bien qu'inondant son enveloppe corporelle, attisent le brasier plutôt que de l'éteindre :

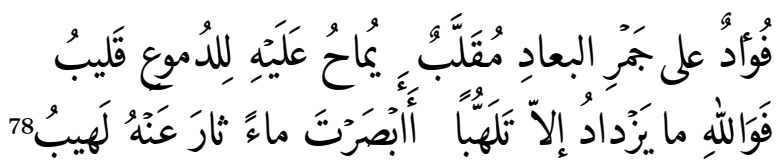

\subsection{Le rakb al-Hijāz}

Les trois poèmes évoquent la caravane de pèlerins en partance pour les Lieux saints, le rakb al- Hijäz, qui apparaît aussi sous l'appellation de «caravane de Médine » $(r a k b \text { Tayba })^{79}$. C'était, nous l'avons vu, un élément primordial du dispositif mis en place pour inciter les croyants à effectuer le pèlerinage. Ce motif constitue à la fois une sorte de trait d'union symbolique entre le sujet et l'objet de son désir et une cause de déchirement pour lui puisque, comme nous le verrons, des obstacles l'empêchent de rejoindre le convoi. Dans la dāliyya, la mention des pèlerins sur le départ (murtahil) est introduite par un wāw rubba:

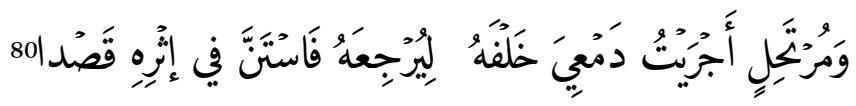

Tout le passage qui suit (v. 24-30) est marqué par la tension entre l'intention exprimée par le sujet de se joindre à ces hommes et son impuissance à réaliser cette aspiration. L'atmosphère bédouine et arabique du poème est renforcée par l'insertion de toponymes (v. 29: Najd, une nouvelle fois, Ḥājir), de noms faisant allusion à des personnages liés à l'Arabie (v. 29: Da'd et Su'dā, noms de femmes fréquemment employés dans la poésie ancienne), de termes techniques dénotant la marche des montures (v. 30 : al-nașs wa-al-wakhd) et du nom himā.

Dans la $b \bar{a}$ ’yya, la caravane est évoquée à deux reprises (v. 10 et 21), l'accent étant mis sur la fatigue, l'éreintement et les frayeurs endurés par ce cortège :

78 Bä’iyya, v. 33 et 34 : “Un cœur que l'on retourne sur les braises de l'éloignement; Sur lui [a été creusé] un puits duquel on tire les larmes / Par Dieu ! Cela ne fait qu'attiser le brasier! As-tu déjà vu de l'eau faire jaillir des flammes ?".

79 Dāliyya, v. 35-36.

8o Dāliyya, v. 24: "J'ai lancé mes larmes à la poursuite d'un homme en partance pour le faire revenir; elles ont volé vers lui en le suivant à la trace". 


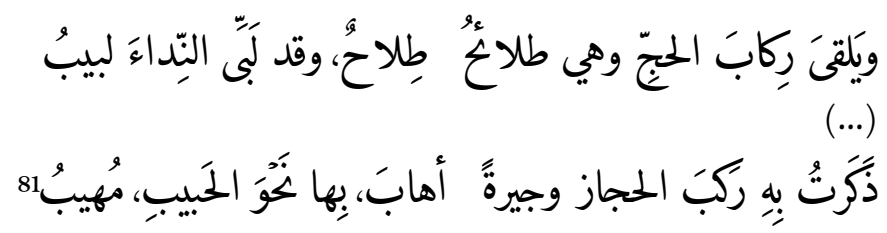

\subsection{Un sujet empêché}

Dans les trois poèmes, le sujet se déclare donc impuissant à réaliser son souhait le plus cher, à savoir rejoindre la caravane qui lui permettrait de se rapprocher de l'objet de sa passion. La ferme volonté affirmée (dāliyya, v. 32 : rumtu, itazamtu) est contrecarrée par des obstacles qui empêchent cette dernière de se traduire en actes. Si le destin (däliyya, v. 32 : miqdār), comme c'est souvent le cas, est présenté comme l'opposant ou le Tiers-actant s'employant à l'empêcher de partir, le sujet insiste aussi sur des fautes ou péchés ('uyūb) commis et rendant son départ impossible (dāliyya, v. 33 : raqīqun badat li-l-mushtarīna 'uyūbuhu). Il procède ainsi à une autocritique qui tourne à l'auto-flagellation, s'accusant d'avoir trop longtemps vécu dans la légèreté et la frivolité, comme dans ce vers de la hẫiyya:

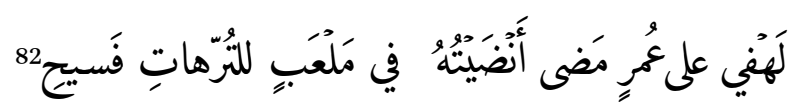

Le portrait qu'il brosse de lui-même dans la dāliyya est tout aussi peu flatteur. Aux raisons déjà invoquées pour expliquer sa paralysie s'ajoute celle de son âge déjà avancé83 :

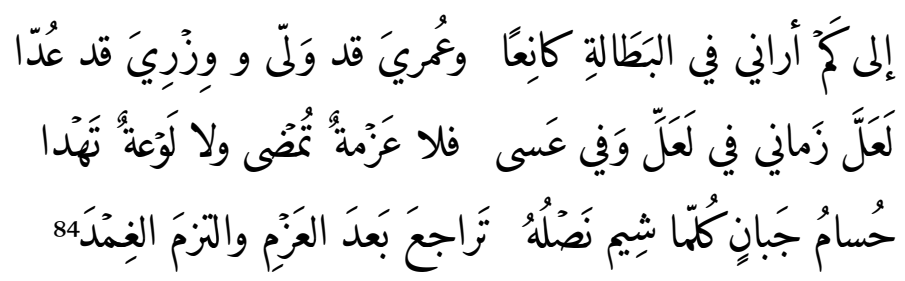

$81 B \bar{a}^{\prime} \bar{y} a$, v. 10 et 21 : "Il rencontre la caravane du pèlerinage : chameaux éreintés, exténués, alors que l'homme avisé a répondu à l'appel [...] Il m’a rappelé celui qui appelait à grands cris les chameaux de la caravane du Hedjaz et des voisins de Dieu, [sur le chemin] les conduisant à leur aimé".

$82 H \bar{a} \bar{y} y a$, v. 25 : "Hélas! J'ai gâché ma vie passée en m’adonnant à toutes sortes de jeux frivoles".

83 La vieillesse n'est qu'un facteur parmi tous ceux qui, non précisés, peuvent constituer un obstacle. Dans tous les poèmes de ce type, Ibn al-Khațīb cultive le flou quand il s'agit de nommer ce qui l'empêche de partir. Voir à ce sujet F. Tahtah, Al-ghurba wa-al-hanin, 334.

$84 D a \bar{a} l \bar{y} y a$, v. 59-61: "Jusqu'à quand me verrai-je garroté, [contraint à] l'inaction, alors que ma vie me tourne déjà le dos et que pèse sur moi le fardeau de mes péchés? /Ma vie s'est épuisée dans des 'peut-être' et des 'il se peut', sans jamais voir une résolution se traduire 
Pour être en capacité de partir, le sujet devrait au préalable avoir «purgé ses dettes » (bā̄iyya, v. 15: wa-tuqdā duyūnī ba'da-mā mațala al-madā). Cette condition lui paraissant impossible à remplir, il n'a donc pas d'autre choix que celui d'accepter le départ et l'éloignement de la caravane. Son seul adjuvant, pour lutter contre la tristesse (asan) et la séparation (bayn), est sa constance $(s ̧ a b r)$. Tristesse, séparation et constance sont personnifiées sous la forme de combattants, mais la bataille qui s'engage tourne vite à l'avantage des deux premiers :

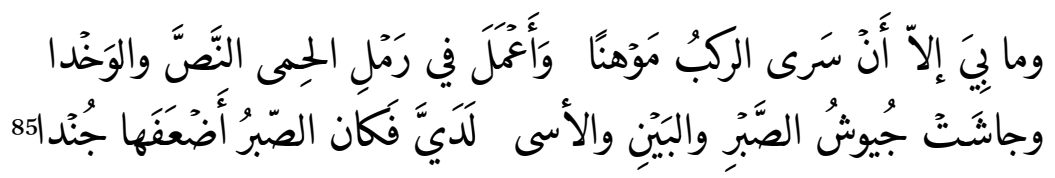

Ce départ provoque chez le sujet une violente émotion (v. 30-31) qui l'amène à s'identifier à un oiseau aux ailes blessées incapable de suivre ses congénères :

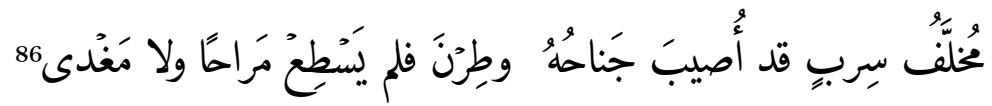

\subsection{Le rahül imaginaire}

Dès lors, on assiste à une sorte de dédoublement du sujet, de disjonction de son corps et de son esprit, le premier étant contraint à l'immobilité tandis que le second s'envole vers son but ${ }^{87}$. Ainsi, dans la däliyya, le sujet envoie ses larmes et son cœur en émissaire au-devant de la caravane (v. 24-25). Dans la hăàyya, l'ambiguïté est encore plus grande : en effet, après avoir précisé que, contraint de renoncer à se rendre physiquement au Hijāz, son voyage s'effectuera par la pensée :

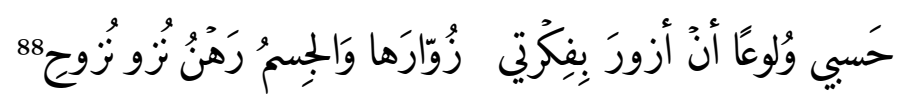

en action et sans jamais voir s'apaiser mon tourment / A peine la lame d'une épée d'un lâche est-elle tirée du fourreau qu'elle le réintègre, revenant sur sa résolution".

$85 D \bar{a} l \bar{y} y a$, v. 3o-31: "J'ai dû me résigner à [voir] la caravane s'ébranler pour son voyage nocturne, au cœur de la nuit, et lancer ses montures, dans le sable du himāà à vive allure / Les armées de l'affliction, de la séparation et de la constance en moi se sont ébranlées, mais la constance était l'armée dont les soldats étaient les plus faibles".

$86 D \bar{l}$ lìya, v. 35 : "Touché à l'aile, l'oiseau a été laissé en arrière par ses congénères; eux ont pris leur envol, mais lui n'a jamais pu [les rejoindre]".

87 Fatima Tahtah parle de "scission" (infișāl), voir Al-ghurba wa-al-haniñ, 323.

88 Hā̉iyya, v. 11 : "Mon désir ardent devra se contenter de rendre visite à ses visiteurs par la pensée, tandis que l'éloignement gardera mon corps en gage". 
Cependant, à partir du vers 13, le sujet évoque, ce périple sur le mode du réel, décrivant, à la manière traditionnelle, l'atmosphère dysphorique d'une pérégrination nocturne, si bien que son arrivée à Médine semble relever d'une expérience vécue. Parmi les procédés narratifs mis en œuvre pour renforcer cette impression figure l'usage de l'accompli :

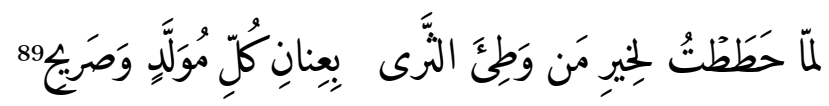

De ce fait, il est difficile, dans ce texte, de percevoir où se situe la frontière entre passé et présent, imaginaire et réalité, expérience et rêve, tant le poète brouille les pistes.

Cette ambiguïté est moins prégnante dans la däliyya. Le périple y est, en effet, clairement annoncé comme étant réalisé "par procuration», puisque le sujet s'adresse directement aux pèlerins (nashadtuka yā rakba l-Hijäz), en utilisant la figure stylistique de l'iltifät, pour leur souhaiter de trouver sur leur route de riches pâturages, de l'ombre et des aiguades, d'être épargnés par les bêtes sauvages et d'arriver au terme de leur voyage sans encombre ${ }^{90}$. Par ce biais, nous suivons donc la caravane depuis son départ jusqu’à son arrivée à Médine (Tayba) ${ }^{91}$. C'est alors que le sujet charge cette caravane imaginaire de le représenter auprès du Prophète :

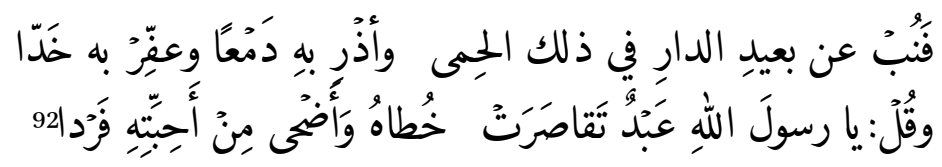

Dans ce poème, le sujet revient encore une fois au-devant de la scène après l'éloge du Prophète, placé au centre de la composition. Une séquence introduite par la formule a-lä layta shírì nous projette de nouveau dans un rahịl imaginaire montrant le sujet en route vers l'Arabie. L'atmosphère bédouine est renforcée par l'usage de termes relatifs aux camélidés: qilās, pluriel de qalūş, qui désigne une jeune chamelle déjà apte à être montée mais n'ayant pas encore perdu ses dents de devant, dâmir et shimilla, qui mettent respectivement l'accent sur la minceur et la rapidité à la course de cet animal.

89 Hã̉iyya, v. 19: "Lorsque j'ai fait halte pour la meilleure [personne] ayant jamais foulé la terre, tenant les rênes de [ma monture], animal croisé ou pur-sang".

9o Däliyya, v. 36-37.

91 Dāliyya, v. 39.

92 Dāliyya, v. 40-41: "Sois le représentant, dans ce himāa, de celui qui est loin de la maison! Verses-y des larmes et macule une joue de poussière ! / Et dis : 'Ô Envoyé de Dieu! Un de tes serviteurs, impuissant à venir jusqu’à toi, a exposé [à sa place] l'un de ses amis”. 
La présence insistante, dans ces deux vers, de ce lexique bédouin confère à ceux-ci une tonalité archaïsante :

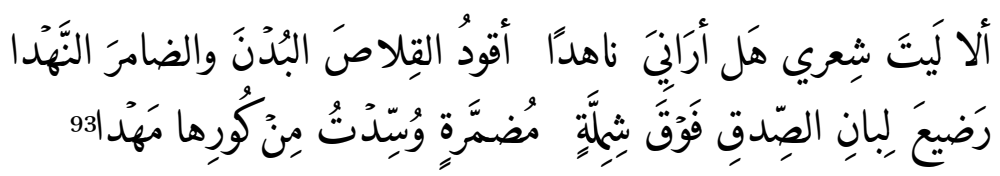

Le sujet s'imagine au sein de la caravane, scandant la marche des chameliers de ses poésies :

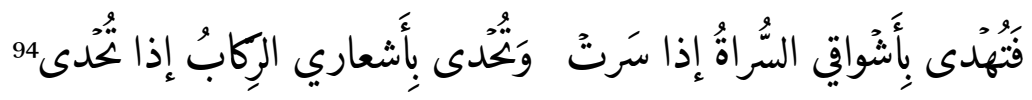

\subsection{L'objet : une ambiguïté persistante}

Nous allons à présent nous intéresser au second pôle autour duquel ces poèmes s'organisent: l'objet du désir et de la quête. Une certaine ambiguïté règne quant à sa nature. Plus exactement, celle-ci n'est dévoilée au récepteur que progressivement. Ce procédé est conforme à la tradition de la poésie mystique, qui entretient le flou quant à l'identité de l'aimé.

L'objet apparaît sous plusieurs formes dans ces odes. Il est d'abord présenté comme un lieu cristallisant la nostalgie du sujet et son désir brûlant. Ce lieu se révèle par la suite être la métonymie de celui auquel il est intimement relié, à savoir, bien sûr, le Prophète.

Ainsi, dans la dāliyya, la première évocation de l'objet intervient au v. 11 et inaugure une nouvelle séquence. Le nom bilādun, placé en incipit de ce vers, nous informe que l'objet de la nostalgie du sujet est un pays auquel son âme est liée et qui est responsable de ses insomnies:

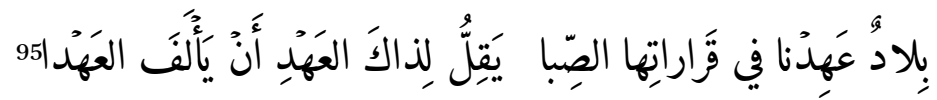

93 Dāliyya, v. 63-64: "Ah! Me verrai-je un jour, me précipiter [vers ces lieux], à la tête de jeunes chamelles grasses et d'une autre très mince mais néanmoins charnue / Nourri du lait de la sincérité et montant une chamelle rapide à la course et dressée à la docilité, sa selle en guise de berceau ?".

94 Dāliyya, v. 65 :"En chemin, les voyageurs nocturnes sont guidés par mes désirs, et les montures sont stimulées par mes poésies".

95 Dāliyya, v. 11 : "Un pays qui fut le théâtre de notre amour de jeunesse; bien rarement tenus sont les engagements pris en ce temps [de la jeunesse]". On note, dans ces vers, la présence obsédante de la racine ' $h d$, qui met l'accent sur la notion de pacte et de fidélité, même si, dans le second hémistiche, nous sommes en présence d'une paronomase (jinās tāmm) qui répète le nom ' $h d$ dans des acceptions différentes. Un peu plus loin, au vers 14, on note l'emploi des deux verbes 'āhada et 'āqada qui renforcent encore cette insistance. 
Mais quel est ce pays? On pourrait d'abord penser que le poète s'apprête à évoquer son pays natal, le Royaume de Grenade. En effet, ce lieu est d'abord présenté comme le pays des amours juvéniles $(s ̦ i b \bar{a})$. Néanmoins, dès le vers suivant, nous découvrons que cette terre est plantée d'espèces végétales arabiques : le saule (al-bān), l'armoise ( $a$ l-shĭh) et la myrte ou bois d'aloès (al-rand). Plus loin, l'ambiguïté est totalement levée, dévoilant que ce pays vers lequel convergent tous les sentiments nostalgiques du sujet n'est autre que l'Orient:

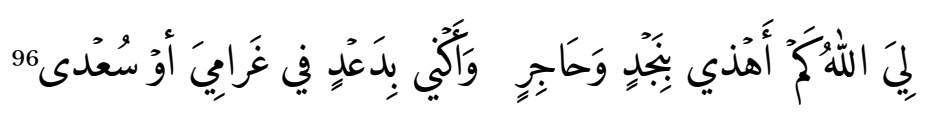

Plus loin encore, un procédé de focalisation resserre l'espace autour du tombeau du Prophète (al-qabr al-muqaddas, al-lahd), lieu qui diffuse une lumière capable de soigner les cœurs les plus durs et les yeux chassieux :

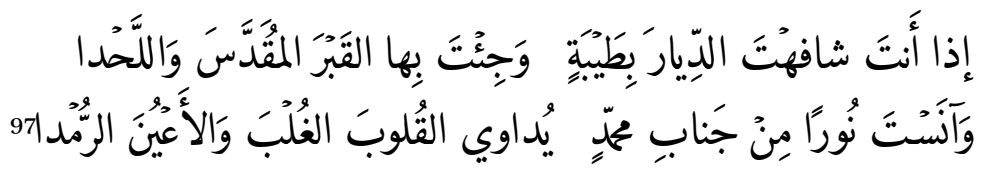

De cet espace sans pareil auquel aspire si fortement le sujet, émane un parfum délicieux:

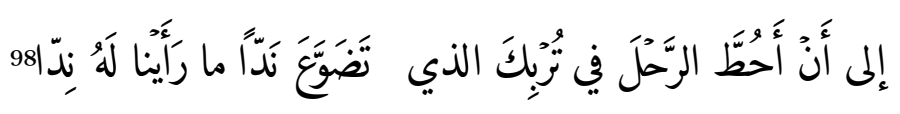

Dans la hăàyya, de la même façon, il est tout d'abord question d'un lieu qualifié de himāa, terme complexe et répété deux fois dans le premier hémistiche du neuvième vers :

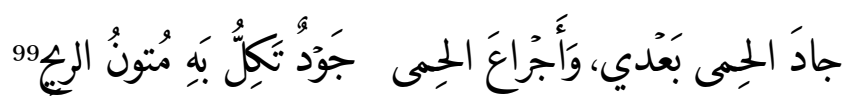

Depuis la période préislamique, où il désignait un riche pâturage déclaré interdit d'accès et d'usage par celui ou ceux qui s'en étaient arrogé la jouissance ${ }^{100}$,

96 Dāliyya, v. 28 : "Dieu ! Combien de fois [m’entend-on] délirer à propos du Najd et de Hâajir, et appeler Da'd et Su'dā sous le coup de la passion !".

97 Dāliyya, v. 38-39: "Lorsque tu t'es approché des demeures à Médine et que tu t'es rendu au tombeau sacré / Et que tu as été baigné par une lumière [irradiant] l'espace de Muhammad, laquelle guérit les cœurs insensibles (car trop épais) et les yeux chassieux".

98 Dāliyya, v. 65 : "Jusqu'à ce que je pose le pied sur ta terre, qui exhale un parfum d'ambre gris et ne ressemble à rien de ce que nous connaissons".

99 Hẳiyya, v. 9: "Qu'après moi le himāa et ses terrains sablonneux reçoivent une pluie si abondante que le vent peinera à la charrier".

100 Voir Chelhod, "Himā". 
le nom himā est investi d'une forte charge symbolique, liée à l'idée d'un lieu protégé et défendu. Ce vers reprend une thématique traditionnelle du nasīb talalì exprimant le vœu que ce lieu vers lequel vont toutes les pensées du sujet bénéficie, en son absence, de la clémence des éléments et soit copieusement arrosé.

Dans le vers suivant, le lieu cristallisant la nostalgie est évoqué, cette fois, par un nom dénotant les demeures par excellence, celles auxquelles on est viscéralement attaché : al-manāzil :

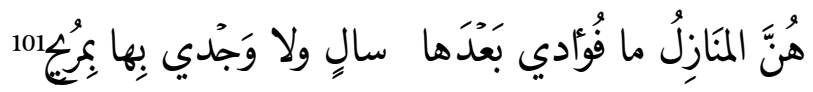

Ce n'est que beaucoup plus loin dans le poème que la nature de ce himā est précisée par une annexion et que ce lieu est ainsi mis directement en relation avec le tombeau du Prophète :

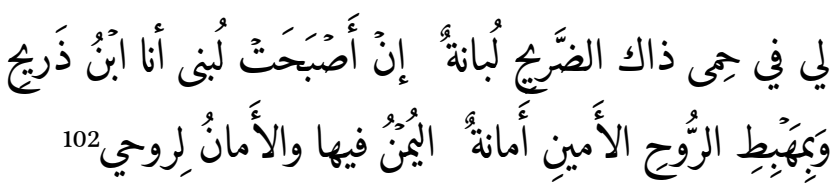

L'allusion faite dans ces vers à un couple mythique d'amants « courtois », Lubnā et le poète Qays b. Dharịh (m. 68/68o), sert à illustrer la nature exceptionnelle du lien qui relie le sujet, qui s'identifie à Qays, au tombeau, assimilé à la femme aimée, Lubnā. Mais l'on ne trouve nulle trace ici du sentiment d'insécurité pouvant naître d'une passion contrariée. Bien au contraire, trois occurrences de la racine '- $m-n$ (amīn, amāna et amān) mettent, dans le second vers, l'accent sur le sentiment de sûreté et de confiance sans égal qui témoigne de la qualité du lien qui rattache le sujet au lieu.

Dans la $b \bar{a}^{\prime} \hat{y} y a$, en revanche, l'identification de l'objet du désir ne passe pas par la phase de la métaphorisation. Si, dans le premier vers, le pronom personnel de deuxième personne, anta ${ }^{103}$, relayé dans les vers suivant par le pronom affixe de même personne, peut encore prêter à confusion, toute ambiguïté est levée au vers 18 :

$101 H \bar{a}^{3} \dot{y} y a$, v. 10 : "Ce sont les demeures : mon cœur, séparé d'elles, ne saurait se consoler, ni ma passion se calme".

102 Hä̉yya, v. 28-29: "[je brûle] d'un ardent désir pour le himā du tombeau et s'il se muait en Lubnā, je serais Ibn Dharīh / En ce lieu où l'esprit sûr est descendu, règnent la sécurité et la félicité, et mon esprit s'y sent protégé".

103 Voir infra. 


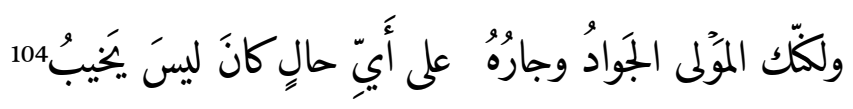

\subsection{L'éloge du Prophète}

Les séquences des poèmes dévolues à l'éloge du Prophète à proprement parler ne se départissent pas du ton de dévotion lyrique qui empreint l'ensemble de la composition. L'existence d'un lien privilégié et individuel unissant le poète et Muhammad y est sans cesse réitérée. Dans la dāliyya, l'adresse au Prophète, comme nous l'avons dit, se fait par l'intermédiaire des pèlerins dont nous avons suivi la progression jusqu'au Hijāz. Léloge (midḥa) y est présenté comme le seul moyen dont dispose le sujet, contraint de vivre le moment de la rencontre à distance et par procuration, pour rejoindre le Prophète. C'est une manière, pour Ibn al-Khațîb, de nous dire la capacité du discours poétique à effacer la distance, permettant ainsi à la clémence (raḥma) de Muhammad de l'atteindre:

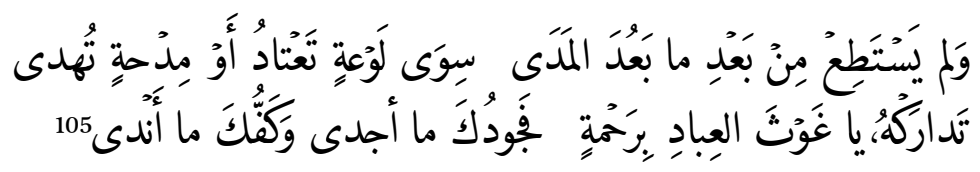

Contrairement à ce qui se passe dans d'autres madāih nabawiyya, il n'est pas question, dans cette qașīda, des miracles (mu jizāat) attribués au Prophète ${ }^{106}$. Léloge se concentre avant tout sur les vertus exceptionnelles qui lui ont été conférées par Dieu, les shamāil ou dalāil al-nubuwwa qui, depuis le début du $\mathrm{XI}^{\mathrm{e}}$ siècle, étaient convoquées en prose comme en poésie quand il s'agissait de désigner le Prophète ${ }^{107}$. La générosité et la protection des croyants sont les premières évoquées. Le vers 43 , que nous venons de citer, met l'accent sur la première ( fa-jüduka māajdā wa-kaffuka mā and $\bar{a})$, tandis que le vers 44 insiste sur la seconde :

$104 B \overline{a ̈}_{\text {iyya }}$, v. 18 : "Mais tu es le seigneur généreux, et, quelle que soit sa situation, celui qui vit près de lui ne pourra jamais être déçu".

105 Dāliyya, v.42-43: "Réduit, du fait de la distance, [à vivre dans] un tourment sans merci et [à dire] des louanges vers toi guidées / Offre-lui réparation, Ô toi dont la clémence porte secours aux hommes, car rien n'est plus salutaire que ta générosité et rien n'est plus généreux que ta main".

106 Ainsi, la Burda d'al-Būṣīīi utilise de nombreux éléments dérivés de la Sīra, dans lesquels les miracles, à savoir le Saint Coran, l'ascension nocturne etc ... sont incorporés comme des extensions à l'éloge.

107 Voir Schimmel, And Muhammad is His Messenger, 32-33 et 180-181. Lauteur mentionne que ces qualités et vertus furent rassemblées à cette époque par les savants (par exemple Tha'labī (m. 427/1035)) et constituées en genre littéraire. 


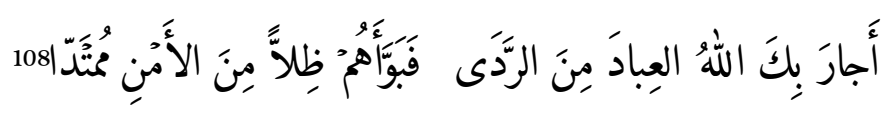

Dans les deux cas, les images convoquées (la main ruisselante, l'ombre étendue) constituent des réminiscences des motifs les plus fréquemment usitées dans le madīh depuis l'époque la plus ancienne mais font aussi écho à des expressions coraniques ${ }^{109}$.

Ces vertus sont aussi les premiers traits attribués au Prophète dans la $b \bar{a} i y y a$. Il y apparaît, comme nous l'avons vu, sous l'appellation d'al-mawlā al-jawād (v. 18). Dans ce vers et le suivant, le poète insiste sur la fiabilité de la protection accordée par le Prophète : nul ne sera déçu ni ne se sentira oppressé en sa proximité (voir v. 19):

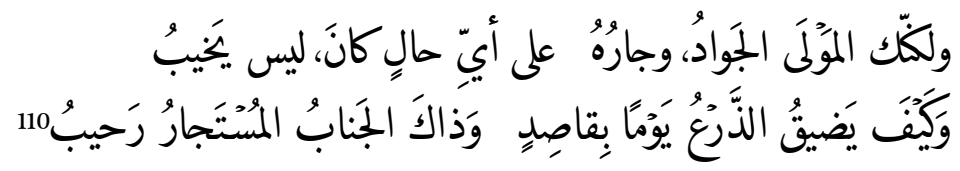

Dans la dãliyya, le poète évoque ensuite la manière dont Dieu a élevé la personne de Muhammad au rang d'être exceptionnel: Il lui a accordé la satisfaction, l'a couronné et revêtu de gloire, a purifié son cœur, l'a couvert de lumière et l'a doté d'une droiture sans égal:

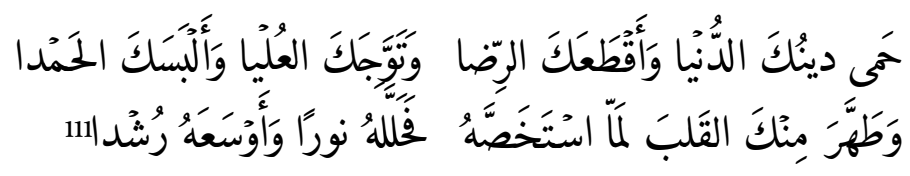

La représentation du Prophète sous la forme d'un être de lumière est une constante que nous trouvons dans l'ensemble de la poésie soufie $\mathrm{e}^{112}$.

Le vers suivant insiste sur le zèle mis par Muhammad à répondre à l'appel divin et à suivre la voie qui lui a été indiquée, ainsi que sur les privilèges qui lui ont été consentis. Ainsi, la soif lui a été à jamais épargnée et son coeur a été préservé contre toute dépravation, nulle rouille ne pouvant l'entacher.

108 Dāliyya: v. 44: "Dieu t’a fait le protecteur des hommes contre la mort, les plaçant ainsi sous de spacieux ombrages, [leur assurant] la sécurité".

109 L'expression zill mumtadd est un intertexte coranique (zill mamdūd, Q $56: 30$ ).

110 Bä̉iyya, v. 18-19: "Mais tu es le seigneur généreux et, quelle que soit sa situation, celui qui vit près de lui ne pourra jamais être déçu / Comment se pourrait-il qu'un jour quelqu'un venant à toi se sente réduit à l'impuissance, alors que l'espace [où s'étend ta] protection est si spacieux?".

111 Dāliyya, v. 45-46. Nous remarquons que le poète passe, dans ces vers, de la deuxième à la troisième personne pour désigner le Prophète, à la faveur du procédé de l'iltifät.

112 Voir à ce sujet: Schimmel, And Muhammad is his Messenger, 126-127. 


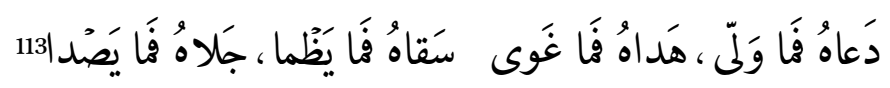

Le vers qui suit, quant à lui, traduit l'adhésion d'Ibn al-Khațîb à la théorie de la préexistence du Prophète Muhammad ${ }^{114}$ :

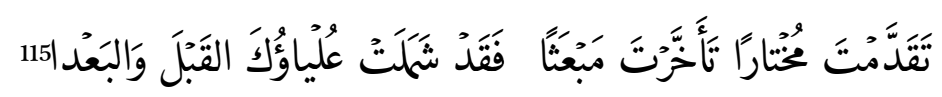

Un degré supérieur est encore atteint quant à la nature supra humaine du Prophète lorsque celui-ci est présenté comme la « la cause de l'univers » ('illat al-kawn) et le «but ultime de tout » (anta l-qaṣdu fíhi):

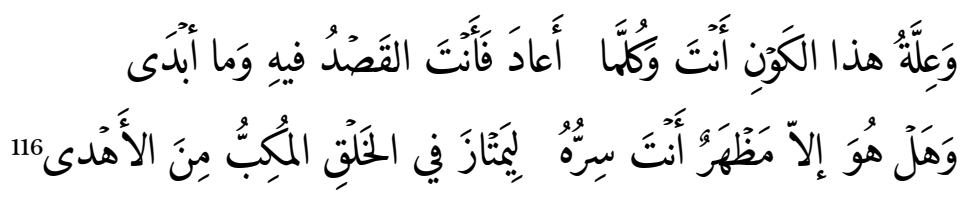

Le Prophète est présenté comme appartenant tant au monde des secrets ('âlam al-asrār) qu'au monde sensible ('ālam al-hiss). Dans le premier, son être diffuse la lumière qui provoqua l'effondrement du tawd lorsqu'elle lui apparut, tandis que, dans le monde sensible, il est un refuge pour tous ceux qui cherchent la guérison et la guidance ${ }^{117}$.

Des procédés stylistiques confèrent à l'ensemble de la séquence une expressivité qui, sans nul doute, visait à produire un effet sur l'assemblée lors de la déclamation de ces odes en public. On note ainsi l'emploi de l'anaphore, avec la répétition de la formule 'alayka șalāt Allāh $h^{118}$, qui était considérée comme un passage obligé dans ce type de poèmes, et l'introduction d'une série d'annexions qualificatives introduites par le vocatif qui présentent le Prophète

113 Dāliyya v. 47 : “ [Dieu] l'a appelé et il ne s'est pas dérobé, Il l'a guidé et il ne s'est pas égaré, Il l'a abreuvé si bien qu'il n'a jamais connu la soif, Il l'a poli de telle façon que nulle rouille ne l'a jamais entaché".

114 Voir à ce sujet Addas, La maison muhammadienne, 28, et Schimmel, And Muhammad is His Messenger, 132-133.

115 Dāliyya, v. 48: "Tu fus le premier élu et le dernier envoyé; ta gloire englobe l'avant et l'après".

116 Dāliyya, v. 49-50 : "Et tu es la justification de cet univers, et tout ce qu'Il a fait, que ce soient des premières fois ou des répétitions, tu en es le but ultime / Cet [univers] est-il autre chose qu'une scène dont tu es le secret afin que, dans la création, celui qui marche le visage abattu soit distingué de celui qui est le mieux guidé". On note dans ce dernier vers un intertexte coranique qui fait écho au verset: a-fa-man yamshī mukibban 'alā wajhihi ahdā am man yamshī sawiyyan 'alā șirāțin mustaqīm (Q 67 :22).

117 Däliyya v. 51-52.

118 Dāliyya, v. 56-58. 
successivement comme «le meilleur des envoyés », «le guide le plus noble », « celui qui rend la vue aux aveugles » :

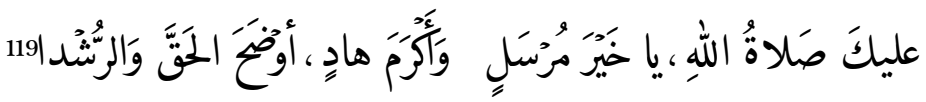

Cependant, au sein même de l'éloge, le sujet intervient pour réitérer son aveu de faiblesse et d'impuissance. Il se représente, en grand danger, suspendu au bord de l'abîme de l'enfer (hāwin 'alā shafan min al-nār) ${ }^{120}$. Après avoir déclaré pouvoir se rapprocher de son but ultime grâce à la louange, il minimise à présent cette possibilité dans la mesure où, ayant été loué par Dieu lui-même, le Prophète n'a nul besoin d'un éloge supplémentaire :

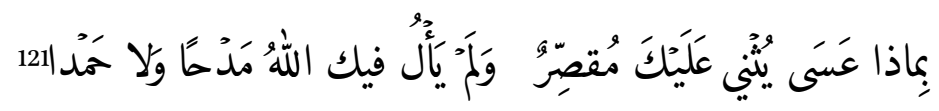

Selon Annemarie Schimmel, la formulation « Dieu lui-même l'a loué » a beaucoup embarrassé les poètes ${ }^{122}$, car il était périlleux de chercher à surpasser les louanges du Prophète figurant dans le Coran.

On retrouve cette problématique dans la hăảiyya, où le sujet insiste sur son incapacité à rivaliser avec le texte coranique, dont la faṣăha est inégalable et inégalée :

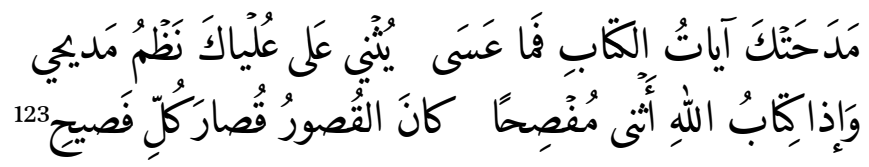

Cette déclaration d'humilité fait toutefois partie des topoï de la poésie laudative et relève de la figure de la prétérition: se prétendre incapable de décrire ou louer un être parfait (qu'il s'agisse, comme ici, du Prophète ou, ailleurs, d'un souverain) n'empêche pas le poète de se livrer à cet exercice. Et c'est ainsi que, dans la dālīya, il entame, à partir du vers 67 , une nouvelle séquence d'éloge de six vers ayant pour objet, cette fois, la naissance de Muhammad. Néanmoins, seuls quelques éléments du riche récit concernant cet évènement sont évoqués.

119 Dāliyya $a$, v. 56: "Que la bénédiction de Dieu soit sur toi, ô meilleur des envoyés et plus noble des guides, manifestation la plus claire de la vérité et de droiture".

120 Däliyya, v. 55.

121 Dāliyya, v. 55: "De quels moyens un homme réduit à l'impuissance dispose-t-il pour te célébrer, alors que Dieu t’a couvert de louanges et de gloire?".

122 Schimmel, And Muhammad is his Messenger, 176-177.

123 Hä̉iyya, v. 36-37: "Les versets du Livre t'ont loué et, de ce fait, les vers de mon panégyrique sont bien incapables de chanter ta gloire / Là où le Livre de Dieu a loué avec éloquence, l'insuffisance est le degré le plus abouti [que peut espérer atteindre] un homme éloquent". 
Parmi eux, figure des événements considérés comme des «miracles». Cette naissance provoque ainsi en premier lieu un ébranlement du monde et lillumination des palais de la ville syrienne de Boșrāa ${ }^{124}$ :

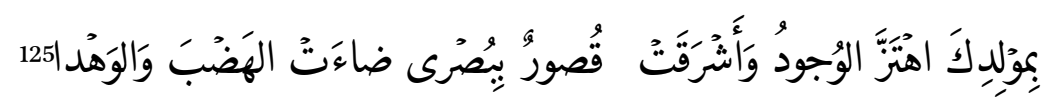

Il est fait référence ici à une tradition selon laquelle la mère du Prophète, Amina, aurait vu, au moment de l'accouchement, sortir de son corps une vive lumière éclairant l'Orient et L'Occident et illuminant jusqu'aux palais de Syrie $^{126}$.

Suit l'évocation du vent de panique s'emparant de symboles particulièrement emblématiques du monde préislamique, les idoles et le palais de Chosroès. Terrorisées, les premières se prosternent tandis que le second s'effondre :

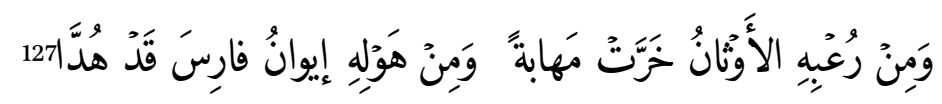

Enfin, les rivières abaissent leur niveau en signe d'humilité et de respect, tandis que l'on assiste à l'extinction du feu des Perses :

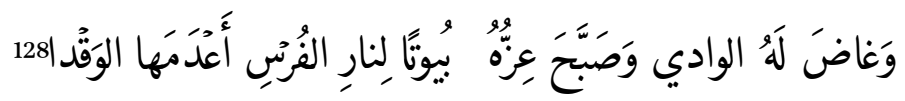

Notons que ces événements furent assez tôt incorporés au récit de la naissance du Prophète. Ils figurent, par exemple, chez Țabarī129 et sont aussi présents en poésie : ainsi, al-Būṣīīi les intègre dans sa Burda et insiste sur l'ébranlement des

\footnotetext{
124 Ville de la Syrie méridionale, fondée par les Romains, Boṣrā était à l'époque un centre commercial important.

125 Dāliyya, v. 67: "Ta naissance a provoqué l'ébranlement du monde et une illumination des palais de Boṣrā qui irradia dans toute la région".

126 Voir Schimmel, And Muhammad is His Messenger, 149. Elle signale que Ḥassān b. Thābit avait déjà évoqué cette lumière dans l'un de ses vers. Au IX ${ }^{\mathrm{e}}$ siècle, celle-ci est déjà traitée comme une réalité matérielle par l'historien Ibn Sacd. Ibn al-Jawzì (m. 597/1200-1) fit mention de l'illumination des palais de Boșrā par cette lumière intense. Et lorsque le Qāḍī 'Iyāạ, dont l'œuvre, comme nous l'avons vu, fut fondamentale dans le développement de la dévotion du Prophète dans l'Occident musulman, décrit la naissance de celui-ci, il ne mentionne qu'un seul « miracle » : cette lumière irradiante.

127 Dāliyya, v. 68. L'effondrement de l'îwān de Chosroès servit aux Arabes de métonymie à la chute de l'empire perse, le nom arabe pour l'empereur perse, Kisrā, évoquant la racine arabe $k-s-r$ (« casser »). Notons que le verbe employé ici (hudda) est coranique (Q 19:90).

128 Dāliyya, v. 69: "L'eau de rivière pour lui disparut dans le sol et sa gloire salua au matin les maisons [abritant] les foyers des Perses, dont elle avait anéanti le feu".

129 Voir Katz, The Birth of the Prophet, 39-40.
} 
colonnes du palais de Chosroès, l'extinction du feu des Perses et le tarissement de leurs sources intervenus le jour de la naissance du Prophète ${ }^{130}$.

Le vers 72 de la dāliyya sert de transition entre l'éloge du Prophète et celui du mamdūḥ, le sultan mérinide Abū Sālim Ibrāhīm. Dans ce panégyrique de facture traditionnelle, dont le nom est cité à deux reprises ${ }^{131}$, l'accent est mis sur la légitimité religieuse de cette dynastie, notamment avec l'emploi de la racine $k h-l-f$, sur laquelle sont formés les substantifs khiläfa (califat) et khalîfa (calife). Les Mérinides sont décrits châtiant sévèrement leurs ennemis et remettant les hommes en perdition dans le droit chemin. Le poète exalte aussi, sans surprise, leurs bienfaits notoires et leur sagesse exercée sans ostentation ${ }^{132}$. Le poème se termine par une déclaration d'allégeance du poète au sultan.

Dans la hăàyya, l'éloge du Prophète, qui se déploie entre les vers 20 et 29 , se caractérise par l'emploi de formules davantage empreintes d'une tonalité soufie. Néanmoins, Lisān al-Dīn se focalise sur les vertus et propriétés du Prophète déjà observées, à savoir : son rôle de protecteur irremplaçable auprès des croyants (ruḥmā ilāhi l-'arshi bayna 'ibādihi et kahf al-anām ${ }^{133}$ ). Il est présenté comme «le meilleur conseiller et l'être le plus digne de leur confiance » (yā khayra mu'tamanin wa-khayra nașīhi $)^{134}$, «le plus fiable transmetteur de la parole divine » (wa-aminnihi l-arḍā 'alā māa yūhì $)^{135}$, «le maître de la véracité » (rabbu l-maqāmi l-șidqi) $)^{136}$. Occupant une place unique auprès de Dieu (yā șafwata Allāhi l-makina makānuhu $)^{137}$, il en est le signe le plus évident, qui répand sa lumière sur le monde :

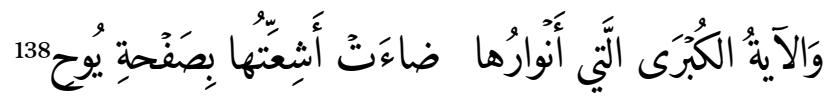

La $b \bar{a} i y y a$ se démarque quelque peu des deux autres poèmes dans sa partie dévolue à léloge. Nous n'y trouvons pas, en effet, de panégyrique « en règle » du Prophète, même si celui-ci est aussi désigné comme «le sceau de la prophétie » (a-yā khātima l-rusli, v. 32). L'accent y est plutôt mis sur la défense de l'islam et la lutte contre l'infidèle, ce passage entrant en résonance avec la

\footnotetext{
13 Al-Būṣīīì, Burda, 70-71, v. 61-64.

131 Dāliyya, v. 79.

132 Dāliyya, v. 77-78.

133 Hāंiyya, v. 20 et 23.

134 Häiyya, v. 3 .

135 Häiyya, v. 20.

136 Häiyya, v. 22.

137 Hāiyya, v. 3 o.

$138 H{ }^{3} i y y a$, v. 21 : "Et le signe suprême dont les rayons de lumière éclairent la face du soleil".
} 
valorisation du jihād caractérisant la période mais aussi, plus généralement, la poésie d'al-Andalus ${ }^{139}$. Cela s'explique sans doute en grande partie par le fait que, comme nous l'avons mentionné, ce poème introduisait une épître rédigée au nom du sultan nasride Muhammad v al-Ghanī bi-llāh. Ainsi, après avoir rappelé la menace planant sur les Musulmans, représentée par des scorpions s'efforçant d'éteindre la lumière de l'islam allumée par le Prophète ${ }^{140}$, le poète évoque les martyrs de la foi tombés lors des batailles menées pour défendre cette religion:

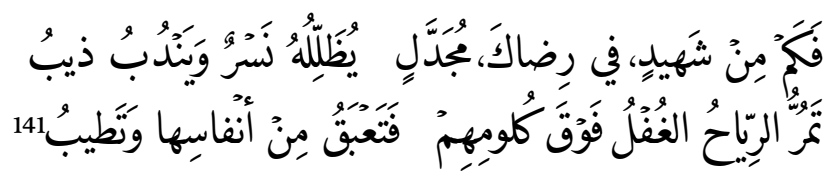

La foi et la dévotion envers le Prophète sont présentées comme un atout essentiel quand il s'agit de mener bataille et d'engranger les victoires contre les Chrétiens :

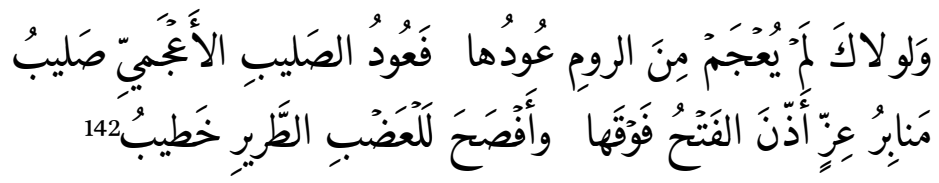

\section{4 Conclusion}

A l'issue de notre étude, comment pouvons-nous caractériser les poèmes d'éloge du Prophète d'Ibn al-Khațîb ? L'une de leurs spécificités réside dans leur caractère composite qui brasse des motifs et des styles appartenant à divers genres poétiques arabes : l'élégie préislamique, le panégyrique de cour traditionnel, la poésie soufie, les Hijäziyyāt du XI ${ }^{\mathrm{e}}$ siècle, la poésie paysagère andalouse, la

139 Cette thématique, nommée istinjād, est très présente, par la force des choses, dans la poésie d'al-Andalus et se développe au rythme des victoires chrétiennes. L'une des références en la matière est sans conteste la qașìda d'Ibn al-Ābbār (m. 658/126o) adressée au souverain hafșide de Tunis au moment où Valence était assiégée par les armées chrétiennes.

140 Bä̀iyya, v. 38-39.

141 Bä̉iyya, v. 40-41: "Combien de martyrs, jetés à terre, pour ton agrément, [reposant] à l'ombre des vautours et pleurés par les loups / En passant au-dessus de leurs blessures, les vents insouciants s'imprègnent de leurs effluves et embaument".

$142 B \bar{a} i y y a$, v. 44: "Sans toi, Le bois des Chrétiens n'aurait pas été marqué de points diacritiques, car le bois de la croix étrangère est solide" et 47 : "Chaires de gloire du haut desquelles la victoire a appelé à la prière, et où le prédicateur a prononcé un prône éloquent [adressé] à des épées extrêmement tranchantes". 
thématique de l'istinjāạ, lui aussi très lié à la production d'al-Andalus, etc ... Ibn al-Khațib manie avec virtuosité toutes ces composantes et les fond dans des compositions très cohérentes organisées autour de la relation individuelle et privilégiée liant le sujet au Prophète.

Si nous nous référons de nouveau à la distinction établie par Suzanne Pinckney Stetkevych entre éloges du prophète d'inspiration soufie et odes dites «de supplication », il apparaît clairement que les textes qui nous occupent sont beaucoup plus proches du premier type que du second ${ }^{143}$. En effet, il n'est pas question, dans ces poèmes, d'une évolution du sujet, d'un trajet qui le mènerait d'une position à une autre. La structure de ces qașídas peut être définie comme cyclique, les retours au pôle « sujet» se multipliant et constituant une sorte d'antienne. Ceux-ci ont pour conséquence une rupture d'équilibre entre les séquences élégiaques centrées sur le sujet et celles dédiées à l'éloge du Prophète à proprement parler, au détriment de ces dernières. Ce déséquilibre entre thuriféraire et objet de l'éloge n'est pas, loin s'en faut, chose nouvelle dans la poésie arabe. C'était d'ailleurs l'une des marques des panégyriques d'al-Mutanabbī. En al-Andalus, Ibn Darrāj al-Qasțallī composa, durant la Fitna du début $\mathrm{du} \mathrm{v}^{\mathrm{e}} / \mathrm{XI}^{\mathrm{e}}$ siècle, des panégyriques qui, à l'instar de ceux de son prédécesseur oriental, auquel il fut souvent comparé, accordaient la part belle au sujet qu'il y installait, la shakwā y prenant nettement le pas sur la louange.

Quoiqu'il en soit, nous espérons que l'analyse de l'ensemble des mada'ih nabawiyya et mawlidiyyāt de Lisān al-Dīn Ibn al-Khațîb, que nous projetons, nous permettra d'affiner ces premiers résultats.

\section{Bibliographie}

\section{Sources}

Būṣīī. al-Burda, Paris, Al-Bouraq, 2013.

Ibn 'Idhārī. Kitāb al-Bayān al-mughrib, section "Almohades", Rabat 1985, 418-425

Ibn al-Khațīb. al-Ihāța fı Akhbār Gharnāța, éd. Y. 'A. Ṭawīl, Beyrouth, Dār al-kutub al-'ilmìya. 2003.

Ibn al-Khațīb. Dīwān, éd. M. Miftāh, Casablanca, Dār al-thaqāfa, 2 tomes, 1989 .

Ibn al-Khațīb. Rawḍtat al-ta'rîf bi-l-ḥubb al-sharīf, éd. M. al-Kattānī, Beyrouth, Dār al-Thaqāfa, 1970.

143 Même si la dāliyya se clôt par un panégyrique des plus classiques, adressé au sultan mérinide. En effet, cette dernière séquence apparaît comme une sorte d'appendice obligatoire bien plus que comme une partie constitutive du madịh nabawī. 
Ibn Sahl al-Ishbīlī. Dīwān, éd. M. F. Dughaym, Beyrouth, Dār al-Gharb al-islāmī, 1998. Maqqarī, A. Nafḥ al-Ṭīb, éd. I. 'Abbās, Beyrouth, Dār Ṣādir, 1988.

Maqqarī, A. Azhār al-riyāọ, Șundūq Ihyā̄' al-Turāth al-islāmī, vol. 1-3, Le Caire, 19391942, vol. 4-5, Rabat, 1978-1980.

\section{Etudes}

Abbādī A. M. "Mu’allafāt Lisān al-Dīn b. al-Khațīb fī al-Maghrib", Hespéris 47 (1959), 247-253.

Addas Cl. La maison muhammadienne: Aperçus de la dévotion au Prophète en mystique musulmane, Paris, Gallimard, 2015.

'Arafat W. "Hassān b. Thābit", in Encyclopédie de l'Islam. Consulted online 14 March 2020 http://dx.doi.org.ezproxy.univ-paris3.fr/10.1163/9789004206106_eifo_SIM_28oo.

Arazi A. "al-Nābigha al-Dhubyānī", in Encyclopédie de l'Islam. Consulted online 14 March 2020 http://dx.doi.org.ezproxy.univparis3.fr/10.1163/9789004206106_eifo _SIM_5703.

Arié R. "Lisān al-Dīn b. al-Khațīb. Quelques aspects de son œuvre", in Atti del Terzo Congresso di Studi Arabici e Islamici, Naples, Instituto Universitario Orientale (1967) 69-81.

Arié R. L'Espagne musulmane au temps des Nasrides (1232-1492), Paris, De Boccard, 1973.

Basset R. "Ka'b b. Zuhayr", in Encyclopédie de l'Islam. Consulted online 14 March 2020 http://dx.doi.org.ezproxy.univ-paris3.fr/10.1163/9789004206106_eifo_SIM_3733.

Buresi P. et Ghouirgate M. Histoire du Maghreb médiéval, Paris, Armand Colin, 2014.

De la Granja F. "Las fiestas cristianas en al-Andalus”, al-Andalus 34 (1969), 1-53.

Encyclopédie de l'Islam (Réd.), "Al-Būșīr̄”, in EI², Suppl. Livr. 3-4, 158-9.

Ferhat H. "Le culte du Prophète au Maroc au XIII siècle : organisation du pèlerinage et célébration du mawlid", in A. Vauchez, éd., La religion civique à l'époque médiévale et moderne (chrétienté et islam), Rome, Publications de l'École française de Rome, 213/1 (1995), 89-97.

Ferhat H. "Chérifisme et enjeux du pouvoir au Maroc", Oriente moderno, Nuova serie, Anno 18 (79), nº 2 (1999), 473-481.

Huici-Miranda, A. "La Toma de Salé por la escuada de Alfonso X", Hespéris, XXXIX (1952), 41-74.

Kably M. Société, pouvoir et religion au Maroc à la fin du Moyen-Âge, Paris, Maisonneuve et Larose, 1986.

Katz, M. H. The Birth of the Prophet Muhammad, London, Routledge, 2002.

Knysh, A. "Ibn al-Khațīb", in M. R Menocal, R. P. Scheindlin and M. Sell, eds. The Literature of Al-Andalus, Cambridge University Press, 2000, 358-371.

Makkī, M. 'A. Al-madāịh al-nabawiyya, Gizeh, al-Sharika al-miṣriyya al-ālamiyya li-l-nashr, 1991. 
Menocal, M. R., Scheindlin R. P. and Sell M. eds. The Literature of Al-Andalus, Cambridge University Press, 2000.

Monroe, J. T. The Poetry of the Sirah Literature, Cambridge History, I, 1983.

Mubārak, Z. Al-madāịh al-nabawiyya fì l-adab al-'arabī, Le Caire, Mușțafā al-Bābī al-Halabī, 1935 .

Rodríguez Gómez, M. D, Peláez Rovira A. and Boloix Gallardo B., eds. Saber y poder en al-Andalus. Ibn al-Jațīb (siglo XIV), Córdoba, Ediciones El Almendro, 2014.

Salmi, A. "Le genre des poèmes de Nativité (mawlūdiyya-s) dans le Royaume de Grenade et au Maroc au XIII e et au XVIII e s.", Hespéris Tamuda 43/3e et 4e trimestre (1956), 335-435.

Santiago, Simón E. de. El polígrafogranadino Ibn al-Jațīb y el sufismo. Aportaciones para suestudio, Granada, 1983 .

Stetkevych Pinckney, S. "Pre-islamic Panegyric and the Poetics of redemption", in S. P. Stetkevych, ed. Reorientations/Arabic and Persian Poetry, Indiana University Press, 1994, 1-57.

Stetkevych Pinckney, S. The Mantle odes, Arabic Praise Poems to the prophet Muhammad, Bloomington et Indianapolis, Indiana university Press, 2010.

Stetkevych J. The zephyrs of Najd, The Poetics of Nostalgia in the Classical Arabic Nasīb, The University of Chicago Press, 1993.

Tahtah, F. Al-ghurba wa-l-hanìn fì l-shi'r al-andalusī, Rabat, Publication de la Faculté des Lettres et des Sciences humaines de Rabat, 1993.

Tițwānī, M. Ibn al-Khațīb min khilāl kutubihi, Tetouan 1954-9.

Vidal-Castro, F. "Ibn al-Khațīb, Lisān al-Dīn”, in K. Fleet, G. Krämer et al., eds. Encyclopaedia of Islam, Third Edition (online). Consulted online on 14 March $2020 \mathrm{http}: /$ dx.doi.org.ezproxy.univ-paris3.fr/10.1163/1573-3912_ei3_COM_30946.

Zwettler M. "The Poet and the Prophet: towards an understanding of the evolution of a Narrative", Jerusalem Studies in Arabic and Islam, 5(1984), 313-387. 